\title{
CHOOSING THE STYLE OF A NEW DESIGN - THE KEY SHIP DESIGN DECISION
}

\author{
David Andrews, FREng, PhD, FRINA, RCNC, University College London, UK
}

\section{SUMMARY}

As a former senior designer of naval vessels and, more recently, a leading researcher in ship design, the author has previously presented a description of the ship design process in terms of the important decisions a ship designer makes in concept exploration. Such decision are made consciously or unconsciously in order to produce a new design or, preferably, any design option. It has been contended in many publications that the first real decision that a ship designer makes, in order to proceed, is the selection of the "style" of the design study or of a specific design option. This term was adopted in order to cover, not just a host of design issues and standards implicit in a given study, but also, at this very initial step, the overall characteristics of any particular study. So the term style could be said to be doubly important.

The current paper considers the nature of the early ship design process for complex multi-functional vessels and then retraces the origins of the particular use of the term, where it was seen as the last of the five elements in Brown and Andrews' 1980 encapsulation of the ship design issues that matter to the naval architect, incorporated in the term " $\mathrm{S}$ to the 5th". This leads on to consideration of the various aspects of design style, many of which could be considered "transversals" as they apply across the naval architectural sub-disciplines and to the component material sub-systems comprising a ship. One of the distinctive advantages of the architecturally driven ship synthesis or Design Building Block approach is that it can address many of the style issues in the earliest descriptions of an emergent design study. Examples, drawing on a range of built Royal Navy ship designs, are presented to show their top-level style characteristics, followed by a series of ship design research studies illustrating how the impact of specific component style aspects can be investigated in early stage ship design, using the UCL Design Building Block approach. Finally, recent research led investigations into integrating ship style into early stage ship design are summarized to demonstrate why the choice of "style" is seen to be The Key Ship Design Decision.

\section{"In matters of importance, style is everything" Oscar Wilde}

\section{INTRODUCTION- STYLE IN EARLY STAGE SHIP DESIGN}

There is an issue with the term "style" when used to describe the design of large scale products, in that style can often be seen as somewhat superficial and highly subjective, hence Oscar Wilde's aphorism, above. It is often taken in engineering or architectural design to be synonymous with appearance and therefore, in most ship designs, seen to be of relatively little importance compared to economic or operational considerations. This is despite the realisation by the US Navy in the Cold War that appearance does matter (Roach and Meier, 1979).

Architects, in straddling the arts and the sciences, historically were seen to adopt particular styles. Thus the American writer on architecture, Witold Rybczynski (2001), says architects are uncomfortable about style, because:

a. their suspicion of it, inherited from reactions to the Modern Movement;

b. adopting a particular style is seen as putting an architect into an " uncreative box"; c. talking of "style" makes architecture (which is a serious business) sound frivolous;

d. seeing style as "subject to the whims and fancies of fashion".

He considers all this is unfounded "as an architecture that recognises style - and fashion - is an architecture for the rest of the world". While this may seem rather rarefied to most design engineers, the issue of subjectivity and a necessary emphasis on human factors, are both key to the nature of style as it is considered it should be addressed in complex ship design. It is in this rather wider sense that is used in the current paper.

"Style" was explicitly incorporated as a characteristic of a ship design by Brown and Andrews (1980) and is the fifth "S" of the "S" 5 " ship design characteristics, seen to be of importance to naval architects in ship design. The other characteristics are those of Speed, Seakeeping, Stability, and Strength (see Figure 1 with a selected example of each $\mathrm{S}^{5}$ characteristic). Each example ship design in Figure 1 is considered to be revealing of that characteristic. Thus for "Speed" (really Resistance and Propulsion) HMS SPEEDY, a hydrofoil Offshore Patrol Vessel, is an example of an attempt to radically change the approach to offshore protection by recourse to employing a very high 
speed "interceptor" (Brown \& Marshall, 1978). The "Seakeeping" example is of a Leander Class frigate slamming in high sea state, despite the hull form of that class being designed from World War II experience in the North Atlantic. The "Strength" example shows a Weapon Class destroyer being subject to an underwater explosive test (UNDEX), to emphasise that naval ship structural design is about surviving weapon effects not just the wave loading from sea. "Stability" is still a comparative measure with the mid-Victorian disaster that instigated statical stability practice, HMS CAPTAIN, with that too radical design's inadequacies revealed by its GZ Curve (Brown, 1983). Finally the example is that of "Style" and is Baker's St Laurent design produced when Sir Rowland Baker was seconded to the Royal Canadian Navy. His frigate design is an example of a consciously "stylised" configuration, showing Baker's intention "to put the RCN's first indigenous design on the map" (Brown, 1983), and so it will be discussed further in Section 4.

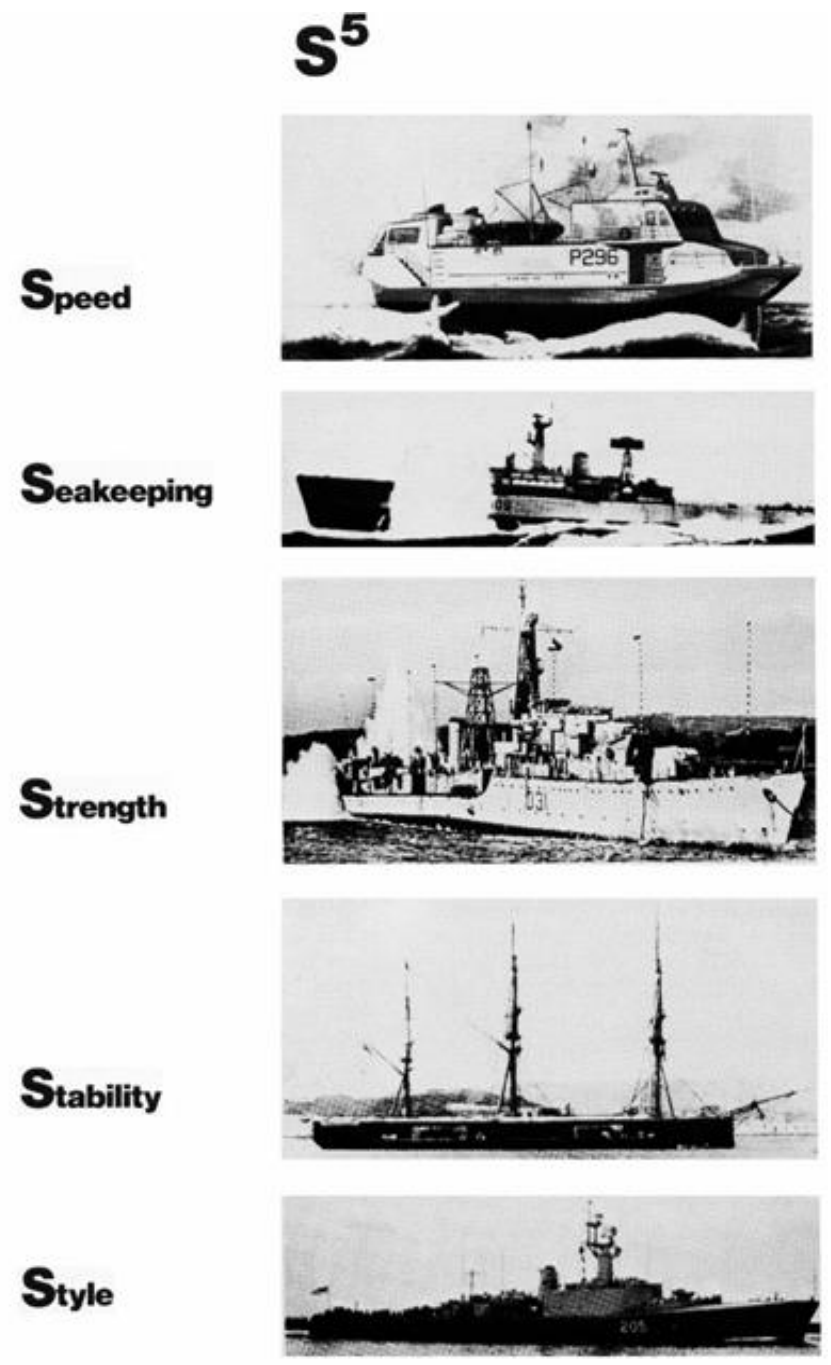

Figure 1: The " $\mathrm{S}$ "" topics that characterise the naval architect's concerns in ship design (Brown \& Andrews, 1980)
However adopting the term style to denote a type of information or ship design characteristic, that sets it apart from other characteristics (or even the accepted subdisciplines) of naval architecture, such as "speed" or structural strength, has some resonance with architectural usage. A slightly different take by Pawling et al (2013) considers the design issues generally grouped under style, to be conceptually different to the other naval architectural disciplines, not because many are unsuited to mathematical analysis (the same was once true of Seakeeping or structural vibration analysis) but because style is a crosscutting concept. Thus a decision, by the ship designer, on a discrete aspect of style explicitly influences a wide range of solution features. Stylistic information also has the key property of addressing uncertainty, since the term is intended to cover both "hard" knowledge (such as adoption of specific structural standards) and "soft" knowledge (such as guidance on ship internal layout). Such knowledge can then be conceptually connected or grouped. In addition, style choices may also be reflected in any weighting factors chosen, should there be multiple and highly disparate criteria involved in the ship designer selecting a design preference from amongst a wide range of design options.

An example of a transversal style choice would be the level and extent of survivability adopted in a naval ship design. A decision on the level of survivability can influence a wide range of overall and detailed design features, such as the choice of signatures and defensive systems (to prevent a hit), the spacing of bulkheads (to resist weapon effects and any subsequent flooding), the mutual arrangement of compartments (to protect vital spaces and aid in recovering from damage) and structural details (to resist the result of underwater shock on the structural hull girder). This survivability example also illustrates another feature of style in that it is cross cutting across the responsibilities of the engineering disciplines involved in a ship design (such as naval architecture, marine engineering, combatant system engineering). In this regard style choices could be said to be particularly critical in decision-making at the crucial earliest stages of complex ship design. It could be argued, however, that the difference between style and the other components of " $\mathrm{S}$ " is a matter of degree, given that all the aspects of ship design interact to a greater or lesser degree with each other.

The paper next discusses, at the macro and major levels of design decision making, the transversal nature of style and presents a specific categorisation of many of the style aspects appropriate to the design of complex ships. This requires outlining some of the characteristics in the overall design process for such vessels. In order to emphasise the importance of choosing the overall style of a new ship design option, in the earliest exploratory stage of early stage ship design (ESSD), Section 3 considers some actual ship designs in which a distinct choice appears to have been made with regard to the overall style of the emergent design. These examples are taken from a range of UK naval and auxiliary ship classes, some of which the author had 
design involvement in (or in the case of the last, prospective, example the author poses some pertinent questions on its viability as a style choice). Section 4 considers the specific cross cutting feature of ship architecture as a means of highlighting the significance of style choice. The subsequent section outlines examples of design studies undertaken by the author's ship design research group at UCL, as each of chosen studies investigated an aspect of style identified earlier in the paper. The paper concludes with an outline of some recent generic research as to how style, as an as an overarching design consideration, might be better addressed in the ESSD of complex vessels.

\section{STYLE ADDRESSING THE TRANSVERSALS AND CATEGORIES OF STYLE}

The style to be adopted in a specific design option is seen to be the key design decision for that option and so is the first design decision (beyond deciding that a certain range of solution options is to be investigated). This is indicated in the overall ship design process representation shown in Figure 2 and taken from the author's COMPIT 2013 paper (Andrews, 2013), where each step or decision selection is explained more fully in the appendix to that paper. Thus Selection of the Style of the Emergent Ship Design is the first design choice and can be seen to impact at the macro, major and micro levels. Macro level denotes the overall style of a design or preferably a design option, whether it is, for example, a conventional warship, a more utility or austere design or a radical configuration, such as a trimaran or SWATH. Below the macro level there can be seen to be some major style choices, such as adopting commercial design standards for a utility helicopter carrier (e.g. HMS OCEAN) or low underwater signature for an ASW frigate (e.g. the Type 23). This level can also cover generic style choices, such as being robust or highly adaptable, or having high sustainability or low manning.

While adopting such style issues is inherent in commencing any design study or a specific option in a series of more exploratory studies, it is important that this is done consciously. This is good design practice since each choice has implications for the eventual design outcome and therefore ought to be investigated before that style aspect is incorporated or rejected. Beyond major style choices are a host of minor style decisions often predicated by the first two levels. These in some sense can be seen as reflecting Ferguson's (1992) observation on engineering design practice, that "Design layout and calculations require dozens of small decisions and hundreds of tiny ones". However, lack of coherence regarding style can mean at all three levels these decisions are not always made with consistency. 


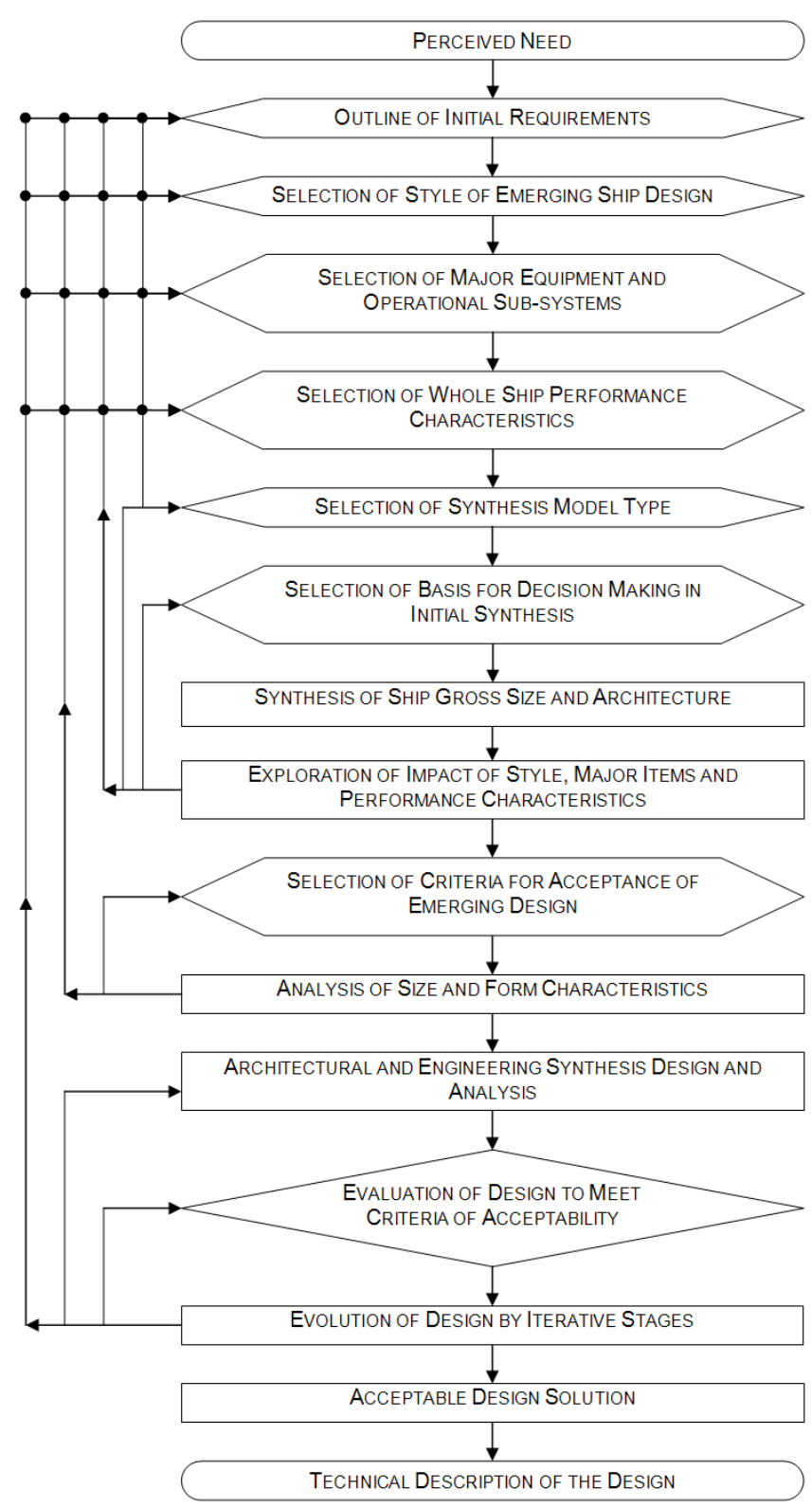

Figure. 2: A representation of the overall ship design process emphasising key decisions with Style as a critical initial choice

The term design style was originally proposed to distinguish a host of disparate issues distinct from the classical engineering sciences applied to ship design. Many of those issues could be seen to be on the "softer" end of the scientific spectrum drawing on the arts and humanities (Broadbent, 1988), whereas the first four terms under the " $\mathrm{S}$ " umbrella are, historically, the principal naval architectural (engineering sciences) subdisciplines associated with a ship's technical behaviour. Thus Style was devised to summarise those other design concerns, which for the case of the naval ship are listed in Table 1 . This very disparate range of issues, have been categorised under some six headings that (ship) designers understand. Thus, for example, concurrent engineering concerns, such as Producibility and Adaptability, are encompassed by the heading Design Issues in Table 1.
Importantly these style issues can make a substantial difference to the final outcome of a design, so their relative impact ought, in the case of a complex ship, to emerge from a proper dialogue between designer and client (or in the naval ship design case, the operational requirements owner). Furthermore, most of these issues have been difficult to take into account early in the design process because, usually, initial design exploration has been undertaken with very simple and, largely, numeric models summarising the likely eventual design definition and giving a (often dubious) feel for the cost to acquire the fabric of the ship (Andrews, 1994). That dialogue can now be informed by also having a graphical representation of the ship's configuration and internal architecture, as is reflected in the process summarised by Figure 2. This process reflects the architecturally (rather than solely numerically) driven synthesis and is 
propounded in the author's Design Building Block (DBB) approach (Andrews, 2003). At the critical early design stages, such a computer graphics based approach can then enable the ship designer to take account of many of the significant issues, many of those listed in Table 1. That these are diverse and not readily or consistently quantifiable means that designers need to exercise judgement, which with stakeholder dialogues are best achieved with an architecturally driven synthesis.

Table 1: Listing of style topics relevant to a naval combatant design

\begin{tabular}{|c|c|c|c|c|c|}
\hline Stealth & Protection & $\begin{array}{l}\text { Human } \\
\text { Factors }\end{array}$ & Sustainability & Margins & Design Style \\
\hline $\begin{array}{l}\text { Acoustic } \\
\text { signature }\end{array}$ & Collision & Accommodation & $\begin{array}{l}\text { Mission } \\
\text { duration }\end{array}$ & Space & Robustness \\
\hline $\begin{array}{l}\text { Radar cross } \\
\text { section }\end{array}$ & Fire & Access & Watches & Weight & Commercial \\
\hline Infra-red & $\begin{array}{l}\text { Above water } \\
\text { weapon effect }\end{array}$ & $\begin{array}{l}\text { Maintenance } \\
\text { levels }\end{array}$ & Stores & $\begin{array}{l}\text { Vertical centre } \\
\text { of gravity }\end{array}$ & Modularity \\
\hline Magnetic & $\begin{array}{l}\text { Underwater } \\
\text { weapon effect }\end{array}$ & $\begin{array}{l}\text { Operation } \\
\text { automation }\end{array}$ & $\begin{array}{l}\text { Maintenance } \\
\text { cycles }\end{array}$ & Power & $\begin{array}{l}\text { Operational } \\
\text { serviceability }\end{array}$ \\
\hline \multirow[t]{4}{*}{ Visual } & $\begin{array}{l}\text { NBC } \\
\text { contamination }\end{array}$ & Ergonomics & $\begin{array}{l}\text { Refit } \\
\text { philosophy }\end{array}$ & Services & Producibility \\
\hline & Shock & & $\begin{array}{l}\text { Upkeep by } \\
\text { exchange }\end{array}$ & $\begin{array}{l}\text { Design point } \\
\text { (growth) }\end{array}$ & Adaptability \\
\hline & Corrosion & & & $\begin{array}{l}\text { Board Margin } \\
\text { (future } \\
\text { upgrades) }\end{array}$ & \\
\hline & $\begin{array}{l}\text { Damage } \\
\text { control }\end{array}$ & & & & \\
\hline
\end{tabular}

The categories adopted in Table 1 reveal the heterogeneous nature of the specific individual style issues, for a complex naval vessel. Thus the various items under Stealth can be seen to be the many different signatures, which a ship has and then needs to reduce to avoid detection, while the Protection items are largely aspects worth incorporating in the ship to mitigate the results of weapon effects, should the Stealth (and any "hard kill" self-defence) fail to be totally effective. However, some of the Protection items are required for normal ship practice, such as corrosion control or for nonweapon considerations, such as collision and firefighting. The Human Factors aspects are little less coherent (and it might be argued rather more solution oriented than those of the urban architectural theorist Broadbent (1988)). Broadbent addresses some 21 "human sciences" that he considers are relevant to human habitation - and hence also likely to be appropriate to HF in ships. HF concerns also relate to the important growth area of automation, which along with micro-ergonomics (e.g. console design) has a strong input to the Protection category, specifically in regard to modern bridge design. Sustainability is a major consideration in naval ship design and could be said to be a major driver, and hence a key hidden decision in the ship's style from the beginning of any ship design study. The list of Margins just makes the point that there are many features and considerations beyond simple margins on the weight/VCG to ensure the ship's stability is adequate beyond the day it is accepted into service. Table 1 also distinguishes those margins required for unplanned (but consistently observed) growth in weight and rise in VCG in-service from Design Margins. The latter are more rightly a Design Issue in Table 1, given they address many measures of uncertainty in design estimates. These margins, across all the weight/space groups, are intended to be absorbed, but not exceeded, as the design and build process progresses to completion.

The last category in Table 1 is clearly the most broad and heterogeneous. Also, generally, such topics have the biggest impact on the final ship design. But this means they need to be recognised as choices and then properly considered with the owner/requirements team from the beginning of studying any design option. Some of these have been the objects of particular investigations by the author's research group at UCL. They are discussed further in Section 5 as examples of the impact on the ship design of considering separately some of these particular issues, where each could be seen as the specific driver of a design from its initiation. It is noticeable that certain of 
these issues can only be adequately investigated in the Concept Phase if the architectural synthesis assumed in Figure 2 is adopted. The other aspect to most of the Design Issues listed is that they have a qualitative or fuzzy nature. Thus, say, Robustness implies a greater degree of that quality than the "norm" for that type of vessel. This then raises the point that such a "norm" for a given new design option ought itself be defined but is often just accepted (or inferred) as being "current practice" or by the adoption of existing standards. There are also exceptions in the listing of the Design Issues category, like Aesthetics, which for most vessels, other than mega yachts and some cruise ships, is seen to be "a luxury". However, even this can be seen to be a simplification, as in the Cold War there was considerable debate in the US naval ship community as to whether the physical appearance of such a ship was part of its political "armament" (Roach and Meier, 1979).

The nature of the design of complex ships, such as cruise ships and naval combatants, is such that the need to emphasise the importance and difficulty of early representation of style issues is seen to be a further complication in the practice of designing such vessels. This is due to there being, additionally, a wide range in the practice of such design. This arises from the degree of design novelty adopted in a specific design option, as is indicated by Table 2 . This shows a set of examples, across the field of ship design, where the sophistication in the design undertaken ranges from a simple modification of an existing ship, through ever more extensive variations in design practice, to designs adopting, firstly, radical configurations and, beyond that, radical technologies. Although in first of the last two categories of Table 2, radical configuration with current technology is often explored, such options are still rarely built, due to the risk of unknowns (usually exacerbated by the lack of a real prototype). Furthermore, radical technology solutions are even more rarely pursued. In part this rarity arises because such radical technology solutions require recourse to design and, indeed, manufacturing practice much more akin to that appropriate to the aerospace industry. Thus new major aircraft projects, typically, require massive development costs (including full scale physical prototypes, some tested to destruction) and additionally need tooling and manufacturing facilities to also be specifically designed and then built, before extensive series production of each new aircraft design can commence. This is of course quite unlike most ship design, be it the ubiquitous bulker or the most sophisticated naval vessel. Such distinctions as those of Table 2 for the design of complex ships suggest any discussion of style needs, at least, to recognise the spectrum of design approach resulting from the novelty of the specific design option being pursued. Such choice on design novelty is key to the initial style choice for a given design study or a variant option in a properly conducted concept exploration (Andrews, 2013).
Table 2: Types of Ship Design in terms of Design Novelty

\begin{tabular}{ll}
\hline Type & Example \\
\hline $\begin{array}{l}\text { second (stretched) } \\
\text { batch }\end{array}$ & $\begin{array}{l}\text { RN Batch 2 Type 22 frigate } \\
\text { and Batch 3 Type 42 } \\
\text { destroyer } \\
\text { Most commercial vessels } \\
\text { and many naval auxiliary } \\
\text { vessels }\end{array}$ \\
simple type ship & $\begin{array}{l}\text { a family of designs, such as } \\
\text { VT corvettes or OCL }\end{array}$ \\
container ships \\
$\begin{array}{l}\text { simple (numerical) } \\
\text { synthesis }\end{array}$ & $\begin{array}{l}\text { UCL student designs } \\
\text { architectural } \\
\text { synthesis } \\
\text { radical } \\
\text { configuration }\end{array}$ \\
$\begin{array}{l}\text { UCL (DRC) design studies } \\
\text { radical technology }\end{array}$ & $\begin{array}{l}\text { SWATH, Trimaran } \\
\text { Ship of 1970s }\end{array}$ \\
\hline
\end{tabular}

\section{EXAMPLES OF STYLE CHOICES IN ACTUAL SHIP DESIGNS}

The following are brief summaries of a series of actually built naval ship designs, where style in an overall configuration has been a distinct choice and also some more specific style choices have been adopted, reflecting some of the more significant issues amongst those listed in Table 1. After the historic examples in the first subsection, clearly contrasting overall style, individual programmes are considered, with the first two examples of commercial style for naval vessels and the next of a short life (margin-less) design intent that was not held to in practice. These can all be seen as Design Issues from Table 1 'though with some specific issues from other style categories, also highlighted.

\section{1 $1^{\text {ST }}$ AND $2^{\text {ND }}$ RATE ROYAL NAVY (R.N.) SHIP DESIGNS}

In an early study into the nature of ship cost Brown and Andrews (1980) drew on a series of R.N. ship designs to point out that ship classes, which had been specifically designated "First rate" or "Second rate" designs, invariably showed that the latter were poor value for money (VFM). This applied to the Queen Elisabeth Class and Revenge Class Battleships, where the latter "cheaper" versions were far less effective and clearly less value for money, in their inability to be upgraded over a thirty years life (Brown, 1999). In WWII the early convoy escorts, the Flower Class corvettes were again poor VFM compared to the later Castles and Lochs. Post War first and second class frigate classes were produced and, while the former (Type 12 Class) led to the very successful Leander Class, the latter (Type 14 Class) were soon disposed of due to their lack of adaptability beyond their design intent as 
convoy escorts (see Figure 3). All these comparative designs could be seen as excellent examples of the overall style choice of each of these designs, from which all the capabilities followed.

\subsection{HMS OCEAN}

Commercial standards were mandated for this helicopter carrier (Figure 4) without this being assessed through any proper concept and feasibility studies. This arose from the adoption by senior naval personnel, not ship designers, of a false costing based on belief that (as yet delivered) the simpler conversion of a merchant ship to a training role (see Section 3.3) could be readily extended to a major amphibious warfare vessel. The Project Manager (the author in 1986-1990) fought the naval staff over adopting such non-naval standards for an essentially high value unit (given its "cargo" of hundreds of troops plus associated equipment and 12 Commando helicopters).

After an abortive capped purchase price acquisition attempt the PM managed to raise the purchase budget but not sufficiently enough to cover the incorporation of quite limited naval standards. The eventual purchase was subsequently criticised by the Ministry of Defence chief marine engineer as this commercial practice substantially increased the engine support requirement for the fleet (due to this one ship's unique engine fit). Needless to say, these support costs were not shown in original cost based decision, given this was obsessed with direct initial procurement cost rather than the "true ownership cost" of the design solution. Interestingly, many have argued that HMS OCEAN has been "good value for money", as it appeared to provide a substantial amphibious lift capability. However that capability has only been exercised in "peacetime roles". The ship has not been used in operations of full naval warfare (rather than usefully in peace keeping), so the jury must be out as to whether this commercially engineered vessel constitutes a "cheap" solution, which is capable of discharging a major naval capability "for real". The extent to which many of the detailed "style issues", largely listed in Table 2 , were predetermined by the style choice of a "commercial ship" emphasises the importance of overall design style.
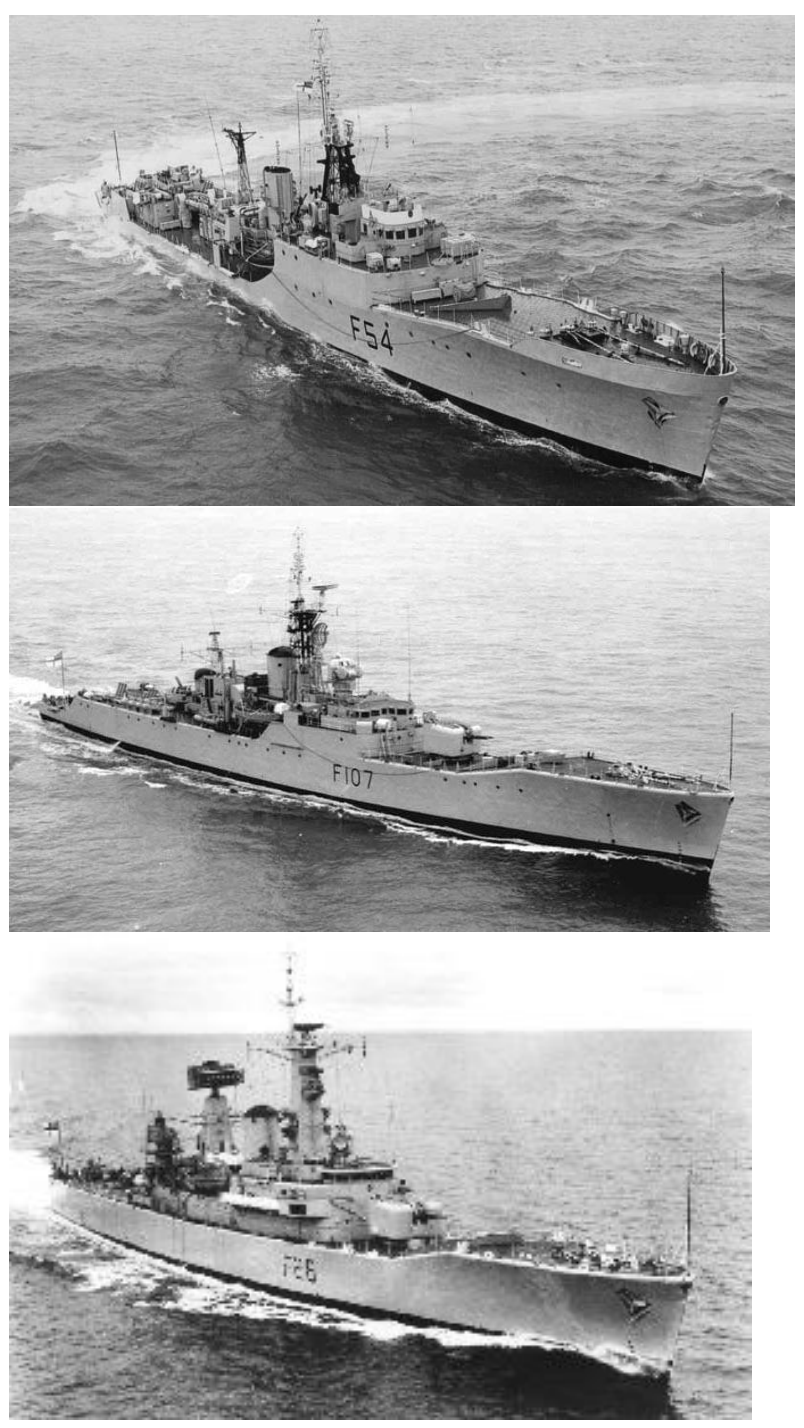

Figure 3: First and Second Rate Post -War Frigates Type 14 vs. Type 12 and LEANDER Class

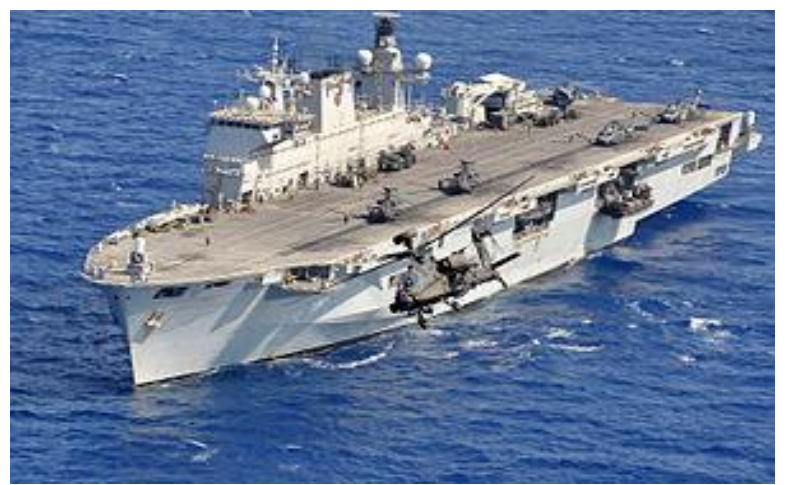

Figure 4: Amphibious Helicopter Carrier HMS OCEAN

\subsection{RFA ARGUS}

This ship was procured by the major conversion of a RoRo containership to helicopter training ship (Figure 5). Having taken on this project in its acceptance phase the author as Project Manager had subsequently to defend to the parliamentary Defence Committee (the HCDC) the 
payment of huge cost overruns on a Fixed Price contract (H.M.S.O., 1989). This case proved naval ship acquisition is a lot more than just engineering design and even conversion to a support role, such as a training vessel, can be demanding. The resultant procurement failure was largely due to several unwise acquisition edicts imposed on the project team, early on in the project acquisition and resulted from a style choice, which could only be described as incoherent in the rush to get what looked like a "quick win". An important negative lesson on how crucial the style decision, in this case to modify a built merchantship to naval operational capability, can be.

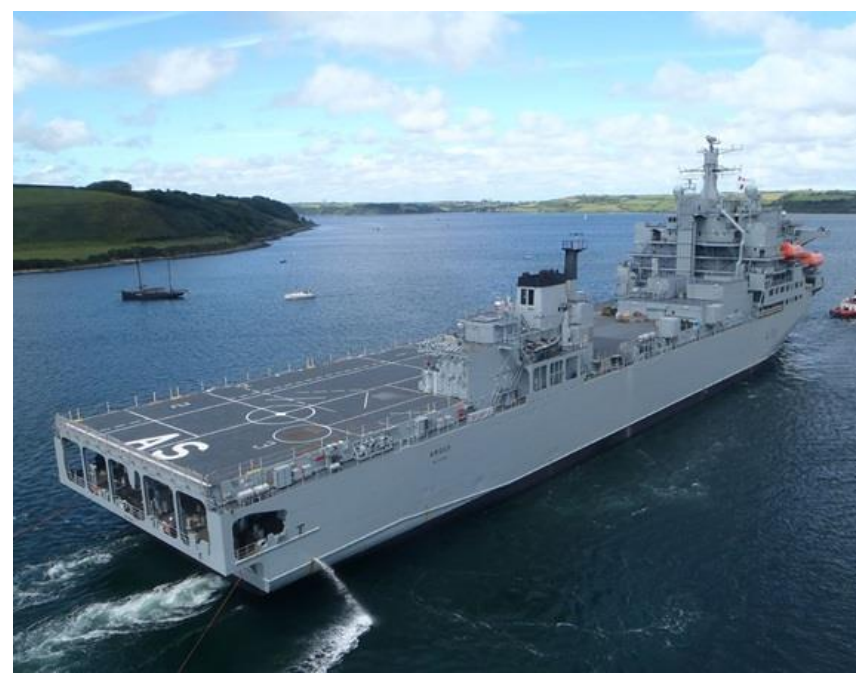

Figure 5: Helicopter Training Ship RFA ARGUS

\subsection{TYPE 23 FRIGATE}

This frigate class evolved from the $105 \mathrm{~m}$ "towed array tug" concept, which then grew in steps $(112 \mathrm{~m}, 118 \mathrm{~m})$ to $123 \mathrm{~m}$ long general-purpose frigate post-Falklands War (and after the official Concept Phase). It was the first flared R.N. hull form (for radar cross section minimisation reasons - see Figure 6) and pioneered a combined diesel-electric and gas turbine (CODLAG) propulsion fit (for ultra-quiet acoustic signature to operate the towed array). Both these features were incorporated from the Concept Design studies and were the two most fundamental ship design decisions, retained from the concept studies despite the very significant growth in size, post-Concept. The style of the design was politically mandated to be short life and "margin less", when everyone in the concept team "knew", despite the Navy Minister's edict, this would not be held. Many ships in the class will be in R.N. service for at least 28 years, rather than the mandated 18 years ship life, and the through life cost of this shows the impact of an ill thought through and then not sustained key style attribute.

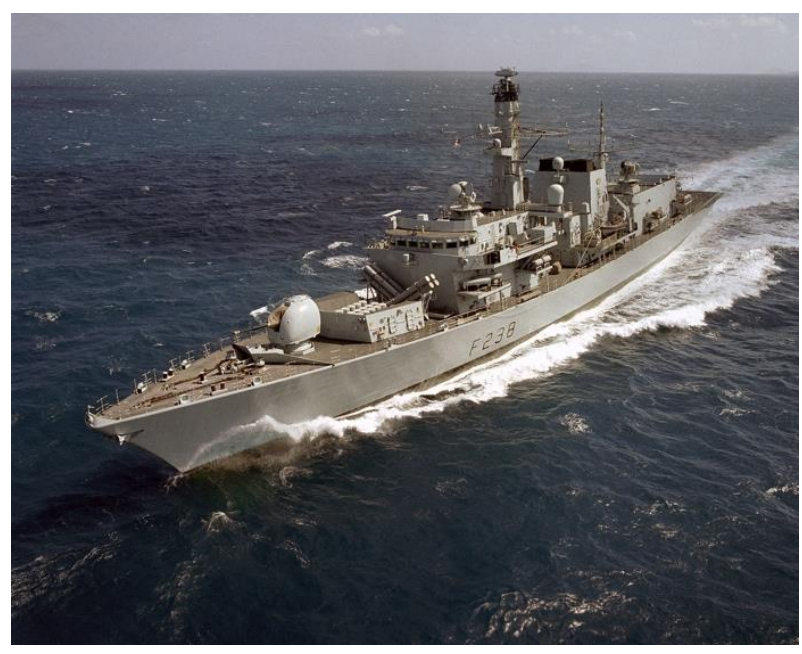

Figure 6: Type 23 Frigate

\subsection{TYPE 31e LIGHT FRIGATE}

This is a new "exportable" light frigate concept proposed in a recent report to the UK Government by the eminent industrialist and naval architect, Sir John Parker. It is seen as an approach to breaking the ever increasing cost of procuring warships and, through adopting more commercial standards and acquisition approaches for a "Second Rate" naval combatant, enabling the Royal Navy to maintain a numerically sufficient surface combatant force (Parker, 2016). The "style" to achieve this could be seen as a return to the concept of a Second Rate, outlined in Section 3.1. Whether in an era of austerity the concept will be more successful than it has been for previous Second Rates must await its design development and then its introduction into service. Given one measure of success of a naval design could be taken to be the longevity of the design in R.N. service, it will be for historians rather than current ship designers to assess whether it follows the examples of Section 3.1 or not.

\section{STYLE WITH AN ARCHITECTURALLY BASED DESIGN SYNTHESIS}

Many of the style issues listed in Table 1 should first be exposed in considering the architecture of the ship. This is both in regard to the overall form (not just underwater hydrodynamic and hydrostatics relevant to the first three $\mathrm{S}^{5}$ aspects but also the overall configuration), which includes the internal layout disposition or architecture. As regards the overall configuration, there are style choices such as whether a multihull is selected or more typically a mono-hull, where there are still high level design choices to be made, such as in the extent and nature of the superstructure configuration (see Piperakis (2014) who considered the survivability of a large hulled/small superstructure frigate option). The manner in which exploration of ship internal configuration and layout can help open up many of the more protracted and less readily analysable aspects of ship design, largely under the style designation, has been taken further by the author. This was firstly proposed in the original exposition of the integration of configuration into early stage ship design 
ship design (Andrews, 1981) and has been developed right up to recent outlines of this approach, which have been adopted in current text books of naval architecture (Tupper, 2013). This section addresses the approach to ship layout or the architecture of ships, for several distinct ship types or "styles", showing the complexity of issues encompassed by style once the architectural component is given its rightful weight in design synthesis and into the rest of early stage ship design.

\subsection{THE EXAMPLE OF FRIGATE ARCHITECTURE} The eminent naval ship designer and historian $\mathrm{D} \mathrm{K}$ Brown's paper on "The Architecture of Frigates" (Brown 1987) drew on his experience of preliminary warship design and on research undertaken by Andrews (1984) and various post graduate students at University College London (Hutchinson, 1981, King, 1985). Brown's paper was largely a comprehensive survey of many of the aspects and constraints impinging on frigate layout design through the various phases of design (termed levels by Brown), from initial design concept (Level 1) through to detailed General Arrangement (Level 3). The design constraints were indicated in his figure reproduced as Figure 7 where an outer ring shows "problem areas" directly affecting a frigate's architecture (e.g. access, noise, vibration, hydrodynamics, structural continuity, survivability, stealth, aesthetics and through life issues). These can be seen to be a mixture of Style aspects (Table 1) and the naval architecture sub-disciplines, showing the complexity of any taxonomy for such an interdependency of issues.

The inner ring of Figure 7 shows elements of the material solution (e.g. accommodation, decks \& bulkheads, shape $\&$ proportions, passages, ladders, services \& machinery arrangements) that are the components of the ship's internal architecture. In keeping with concept of ship style, Brown discussed the range of style-related issues relevant to the layout of a given design (i.e. ship role, modular/cellular features, margins, zoning). He emphasised how, for his Level 1 (for a frigate and similar combatant vessels), the key to the internal layout is the design of the upper or weather-deck disposition of weapons, helicopter arrangements, radars, communications, bridge, boats, seamanship features, machinery uptakes and down-takes, and the access over the deck and into the ship and superstructure. Figure 8 shows an updated version of Brown's frigate configuration, identifying many of the generic weapon, sensor and ship issues in arriving at a balanced ship architecture (Andrews 2003).

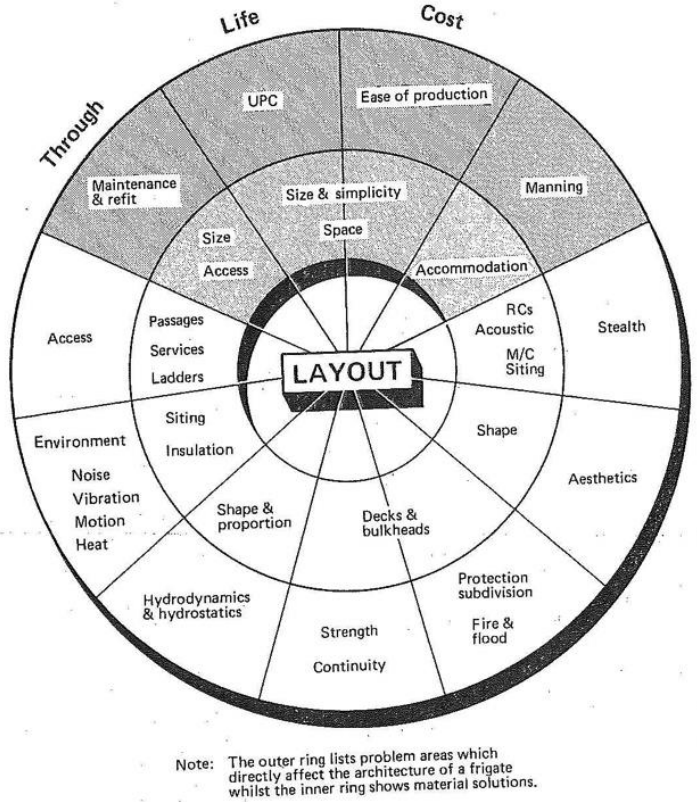

Figure 7: Design Constraints affecting Frigate Layout (Brown 1987)

When one considers the internal configuration of a tightly packed multi-role vessel - the General Arrangement - it is often hard to discern a clear logic, due to the usual practice of trying to pack every compartment in the long narrow "box' resulting from high Froude Number driven hull dimensions. However a good actual example of a coherent layout is that in the first indigenously designed class of frigates for the Canadian Navy - the St LAURENT Class, produced in the 1950s. This was a highly innovative design with a continuous passing deck (unlike previous destroyers and frigates), which also introduced a central cafeteria messing system (Baker, 1955). The design was due the, seconded, Constructor Commodore Baker (later to be Sir Rowland Baker of Dreadnought and Polaris fame (Brown, 1983)). Baker's vision and management of the design commenced with the concept design, which was used to maintain design coherence throughout the design process, despite the high profile nature of the project (Brown 1983). One of the means that Baker used to exercise the control was in the physical architecture of the ship. Thus Baker conceived of a "stylised approach" to the functional arrangement of the ship's layout, see Figure 9, which was robustly maintained throughout the design process. This was despite numerous attempts by "stakeholders" to impose "improvements" - something all too common in complex (and politically sensitive) major projects. That this design was highly successful was shown by its repeat design (RESTIGOUCHE Class) and by the ability of the design to be modernised in service to fully accommodate the large SeaKing ASW helicopter on board a relatively small ship. 


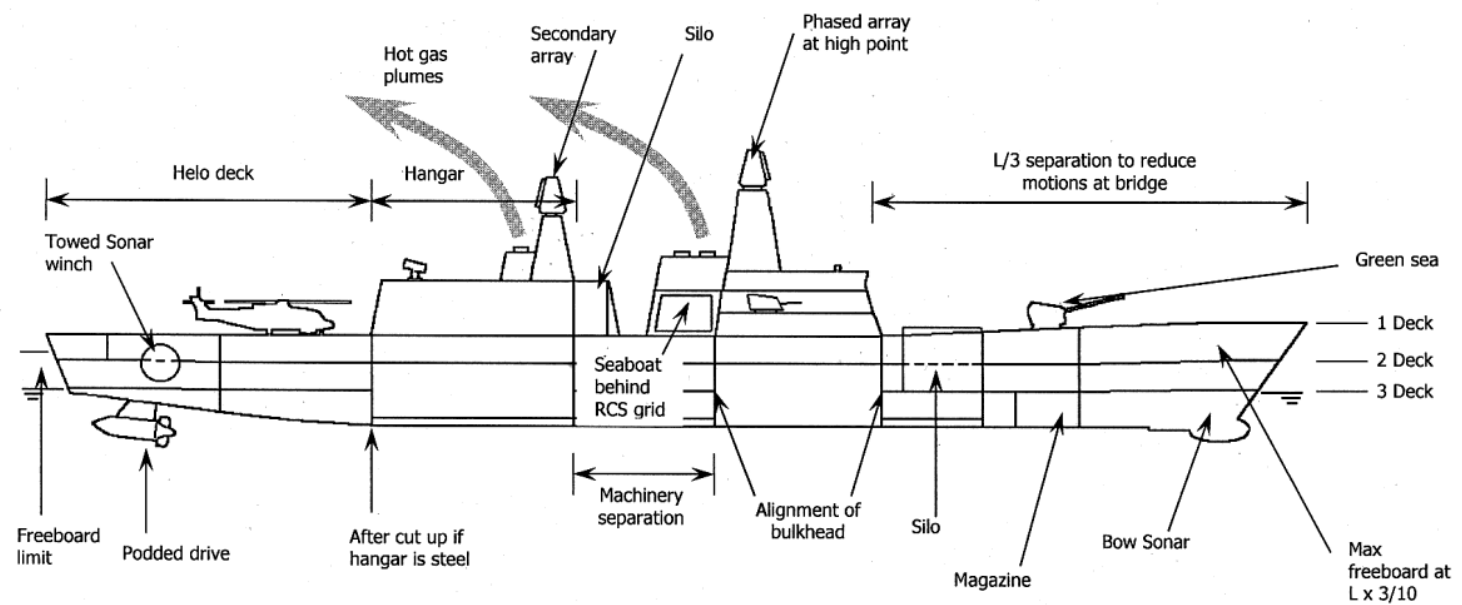

Figure 8: Frigate Layout Considerations (updated from Brown (1987) in Andrews (2003))

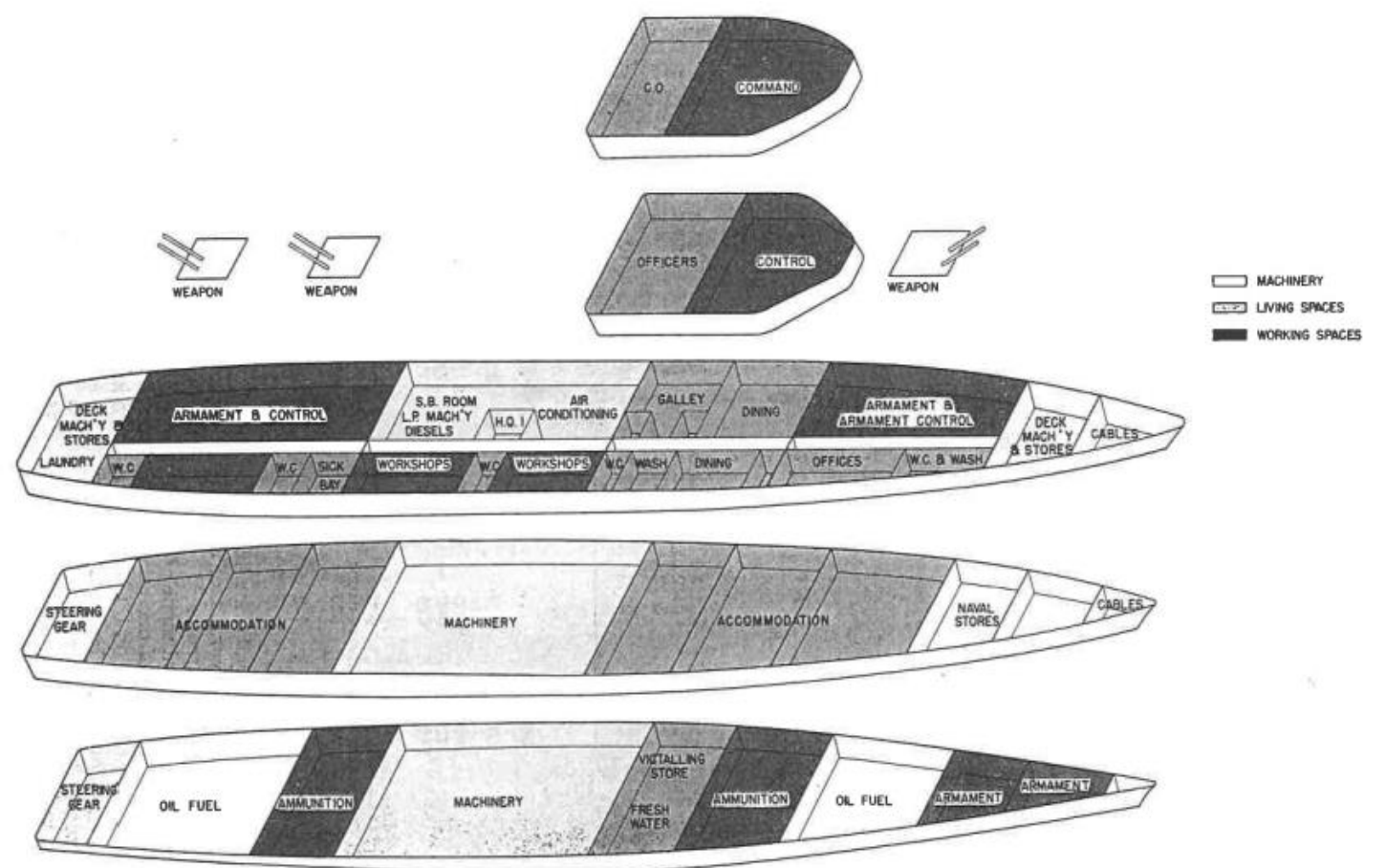

Figure 9: The “Stylised” Layout of Baker's St LAURENT Class Frigates (Baker 1955)

\subsection{CONFIGURATION DRIVEN SHIP DESIGN}

Although the author has long postulated that the design of all warships (and most commercial service vessels) should be driven in large measure by their internal (and upper deck) configuration (Andrews 1981, 2003), it will be recognised that the concept design of certain ship types has to be approached by firstly configuring the spaces required to achieve the primary function(s) of that vessel. Thus, the physical description of a passenger, cruise or ferry ship, can only be produced by commencing with the arrangement of the public spaces and cabins (Levander, 2003). Similarly the configuration of certain large naval vessels, such as aircraft carriers and amphibious warfare vessels, are driven by the spaces required to accommodate the primary "cargo", whether the hangar and flight deck or the well dock and vehicles decks in those specific cases. A prime example of this aspect was presented on the INVINCIBLE Class carriers (Honnor \& Andrews, 1982) in a diagram reproduced at Figure 10. This shows schematically personnel routes, equipment removal routes and stores routes around and directly below the two decks, which dominate any aircraft carrier design, i.e. the flight deck and hangar deck. That paper discussed the need for access from the main through deck, below the hangar, and around the side of the hangar, taking into account the other spatial demands for machinery inlets, outlets and removal routes, as well as features, such as 
boat arrangements and ship ventilation. That paper also pointed out, however, that some important military features also had to be accommodated in the arrangement but had been deliberately omitted from this figure. These included :

- Magazines and weapon movement routes;

- Other important aircraft support spaces and stores;

- The location of ship and force command, control and communications;

- Damage control features.
Although these features would need to be included in order that the evolution of such a complex ship configuration could be properly appreciated, this example - and the previous frigate case - are considered to demonstrate the author's contention in regard to the centrality of a ship's architecture in the early design process and, in style terms, the essentiality of a three dimensional functional integration, being key to the ship design.

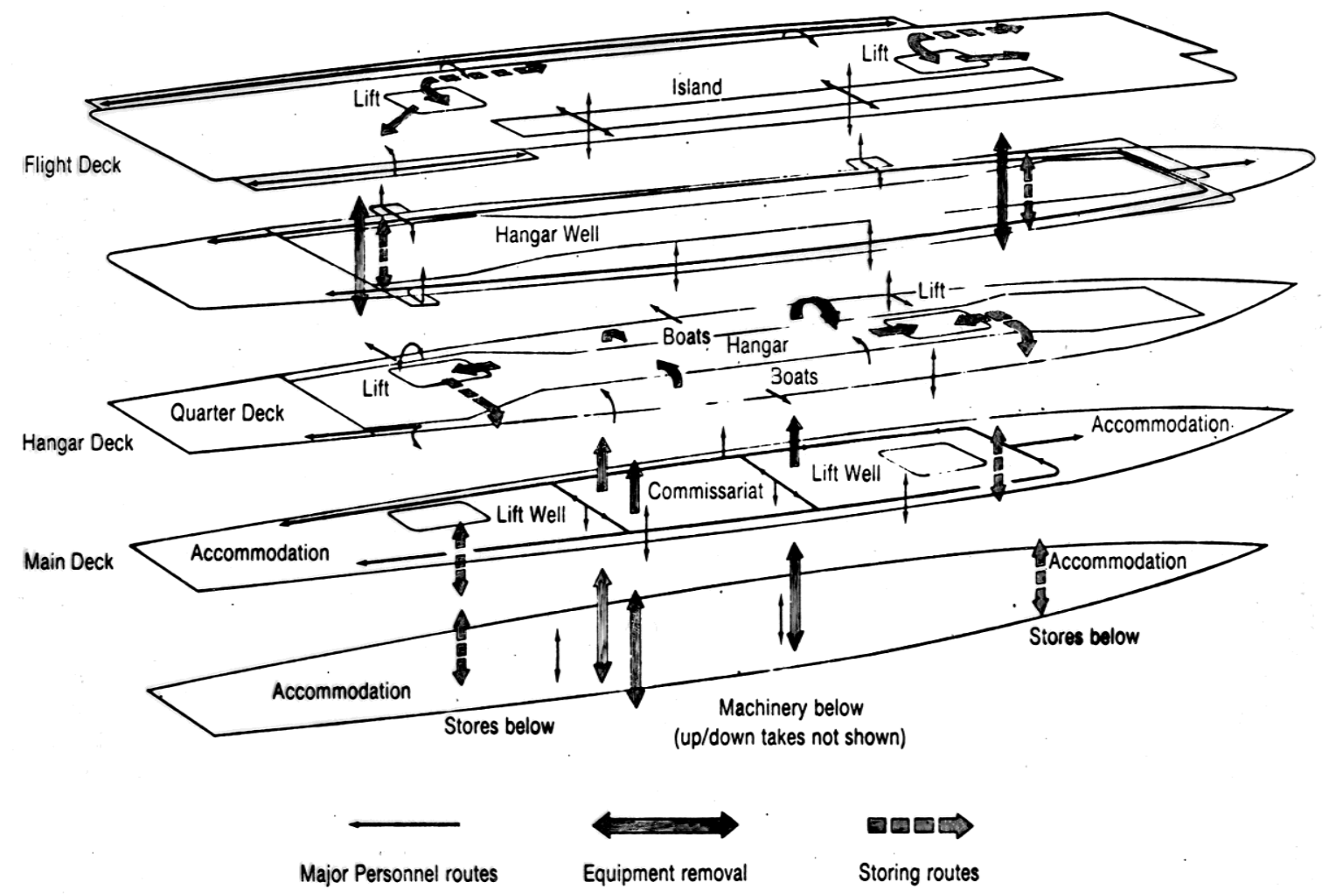

Figure 10: Schematic of INVINCIBLE Class Internal Arrangement (Honnor \& Andrews 1982))

\subsection{DESIGN OF UNCONVENTIONAL HULL} CONFIGURATIONS

A further type of ship style, which necessitates a significantly distinct ship design process is that identified by the penultimate category in Table 2. While unconventional hull types are relatively infrequently adopted as solutions for ocean going ships, they should nevertheless be included in the options considered in any comprehensive exploratory stages of a new ship design. In particular, in the case of the normally displacementborne multi-hulled configurations - like the catamaran, SWATH and trimaran - the architectural design is highly significant. When the initial sizing of ocean-going multihulled vessels is considered, in determining dimensions and form parameters it is apparent that their sizing is not circumscribed by the relatively narrow range of hull parameters, that typical apply to mono-hulls essentially driven by the Froude wave making effect. Consequently the designer, of say a SWATH or trimaran, has to size these vessels on the basis that it is the configuration of their major spaces and how they are disposed between the hulls and the broad cross deck structure, which constitutes the main driver for determining the vessel's dimensions and principal form parameters (Andrews, 2004). As can be seen from Figure 11, the size and shape of the trimaran combatant shown are driven significantly by the disposition of the major operational and habitable spaces, particularly those in the box structure. 

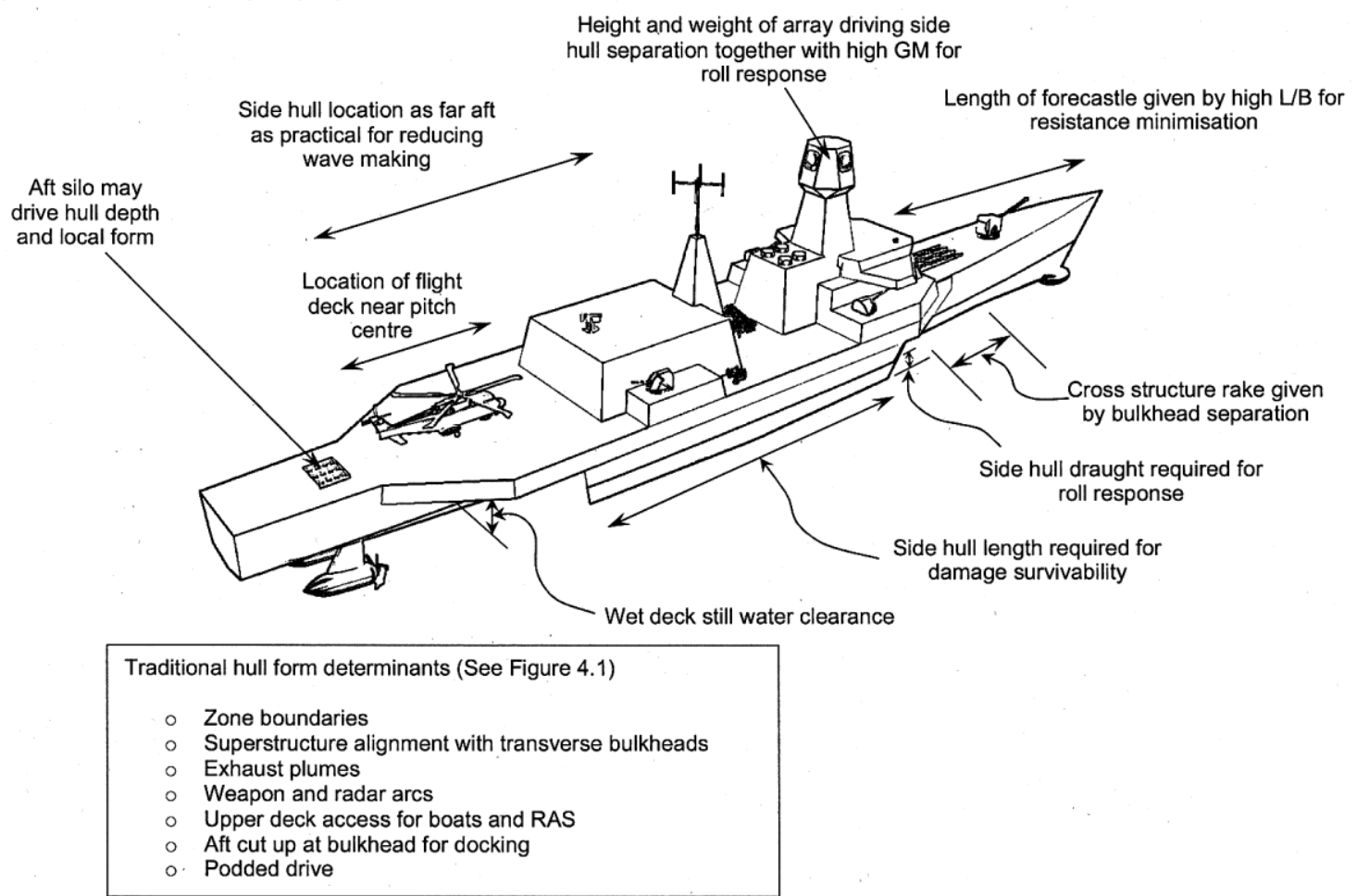

Figure 11: Trimaran Configuration Drivers for a Combatant (Andrews 2003)

\subsection{APPLICATIONS OF THE DBB APPROACH TO OVERALL STYLE INVESTIGATIONS}

The established PARAMARINE ship design system (Munoz \& Forrest 2002) was made able to accept a new module, known as SURFCON, which implemented the UCL Design Building Block approach in a fully integrated manner. Thus the architectural approach to ship synthesis has been fully incorporated within a practical CAD system. The manner in which the SURFCON tool is structured was described following its beta testing by Andrews and Pawling (2003). Two features incorporated in the PARAMARINE version of SURFCON, which were already part of the UCL prototype, were :-

(1) A functional breakdown of the design building blocks adopted for ship description. The categories of the building blocks (i.e. float, move, fight/operation and infrastructure) can be distinguished by their four characteristic colours in the example screen shot of the SURFCON system in Figure 12, plus purple for the main access routes. This breakdown of the Design Building Blocks was introduced to foster the exploration of more innovative configurations as part of Requirements Elucidation (Andrews, 2011), where choice of style is key;

(2) Use of the term Master Building Block to indicate how the overall aggregated attributes of the DBBs would be brought together so as to provide the numerical description of the resultant ship design. The advantage of using the design building block capability of SURFCON as an adjunct to the already established ship design suite of PARAMARINE, is that the audited building block attributes assembled within the Master Building Block could be used directly by PARAMARINE, thereby enabling the necessary naval architectural calculations to be performed to ascertain the balance, or otherwise, of the configuration being derived by the designer.

The DBB approach is intended to foster innovative design solutions and so is neither "hard wired" nor employing predetermined routines to achieve naval architecturally balanced ship solutions. It does need to be used by a capable ship designer, who can then exploit the capabilities of the system to produce coherent and balanced ship design studies. The system, in auditing a new configuration of building blocks, will report to the designer the state of the design. Rather than automatically changing the dimensions and or the hull parameters, which might be the case with a "black box" system, Paramarine-SURFCON will tell the designer where a design study is no longer balanced. Thus the designer can make the appropriate decision on how to proceed with the design at that point in time, drawing on the evidence afforded by the system as to the imperatives for the study at that juncture, including due regard to the chosen style for that design option. In that respect it can be seen to be responsive the subtlety of style based decision-making.

The general procedure adopted in undertaking a new ship design study using the PARAMARINE/SURFCON system can be summarised as follows:

(1) A very broad intent and tentative outline requirement is identified and a design style proposed;

(2) A series of design building blocks are defined or selected (from a library or newly created), containing 
geometric and tentative ship size and a set of hull dimensions postulated;

(3) The design building blocks are located as required within a prospective or speculative configurational space and tentative hull form(s) taking into account the preferred or proposed style;

(4) Overall weight and space balance and performance (e.g. stability, powering) of the design are assessed, using the PARAMARINE naval architectural analysis routines;

(5) The configuration is then manipulated until the designer is satisfied with both the configuration, reflecting the perceived style issues, and the naval architectural balance;

(6) Decomposition of the design building blocks to ever greater levels of detail is undertaken as required, and ship balance / performance maintained at the appropriate level, often exploring further critical style aspects.

Table 3 shows the manner in which this overall procedure is evolved in stages which is presented for the final) design stage for a concept design of the (trimaran) naval combatant in Figure 12 (see Andrews and Pawling (2008) for the details behind each step).

Table 3: The Stages in DBB approach to Ship Synthesis (with the number of blocks indicated for each step for the design in Figure 12)

\section{Design Preparation}

Selection of Design Style

Topside and Major Feature Design Phase (18 to 47)

Design Space Creation

Weapons and Sensor Placement

Engine and Machinery Compartment Placement

Aircraft Systems Sizing and Placement

Superstructure Sizing and Placement

Super Building Block Based Design Phase (47 to 110)

Composition of Functional Super Building Blocks

Selection of Design Algorithms

Assessment of Margin Requirements

Placement of Super Building Blocks

Design Balance \& Audit

Initial Performance Analysis for Master B.B.

Building Block Based Design Phase (110 to 343)

Decomposition of Super Building Blocks by function

Selection of Design Algorithms

Assessment of Margins and Access Policy

Placement of Building Blocks

Design Balance \& Audit

Further Performance Analysis for Master B.B.

\section{General Arrangement Phase}

Drawing Preparation

Each design building block, as the fundamental component of the SURFCON approach, can be regarded as an object in the design space and as a "placeholder" or "folder" containing all the information relating to a particular function within the functional hierarchy. The ways in which the design can be manipulated on the screen are described by Andrews and Pawling (2003). Importantly the "block definition" object permits the designer to add whole ship margins and characteristics, such as accommodation demands, once the "block summary" object has summarised all the information in the top level block in the building block hierarchy. (In effect this is the Master Building Block object.) The "design audit" object then allows the design description to be audited for any of the characteristics selected for monitoring, which typically will include style aspects alongside prime naval architectural capabilities. Results can be displayed using the functional group hierarchy; this "design audit" object is assessed for a range of design infringements, by other objects in the design space, and for the balance of the overall ship design from the whole ship characteristics listed in the Master Building Block.

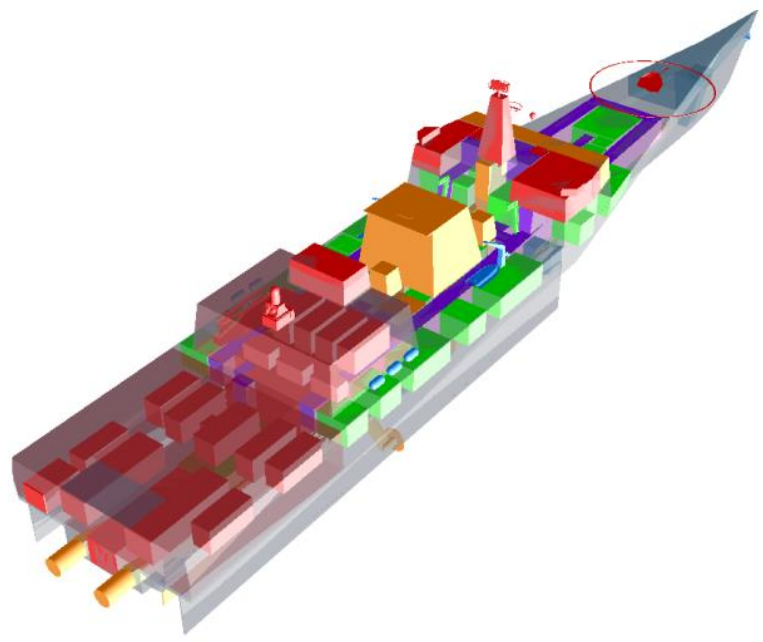

Figure 12: SURFCON Model of UCL DBB Study of LCS Design (Andrews \& Pawling 2008)

A further advantage of the architecturally driven approach is that it enables the concept designer to look at quite different physical configurations for the same set of broad operational requirements. An excellent example of this was the investigation into the operational concept of small littoral craft being transported oceanographically by a fast mothership (Andrews and Pawling, 2004). Figure 13 shows the SURFCON representations of five configurations (e.g. dock ship, heavy lift ship, crane ship, stern gantry ship and open stern ship) and two variants. This shows well the issue of overall style choice in the five distinct configurational options produced. To the extent that they all aim to reach the same operational 
performance the style issue becomes one of whole ship configuration exploration.

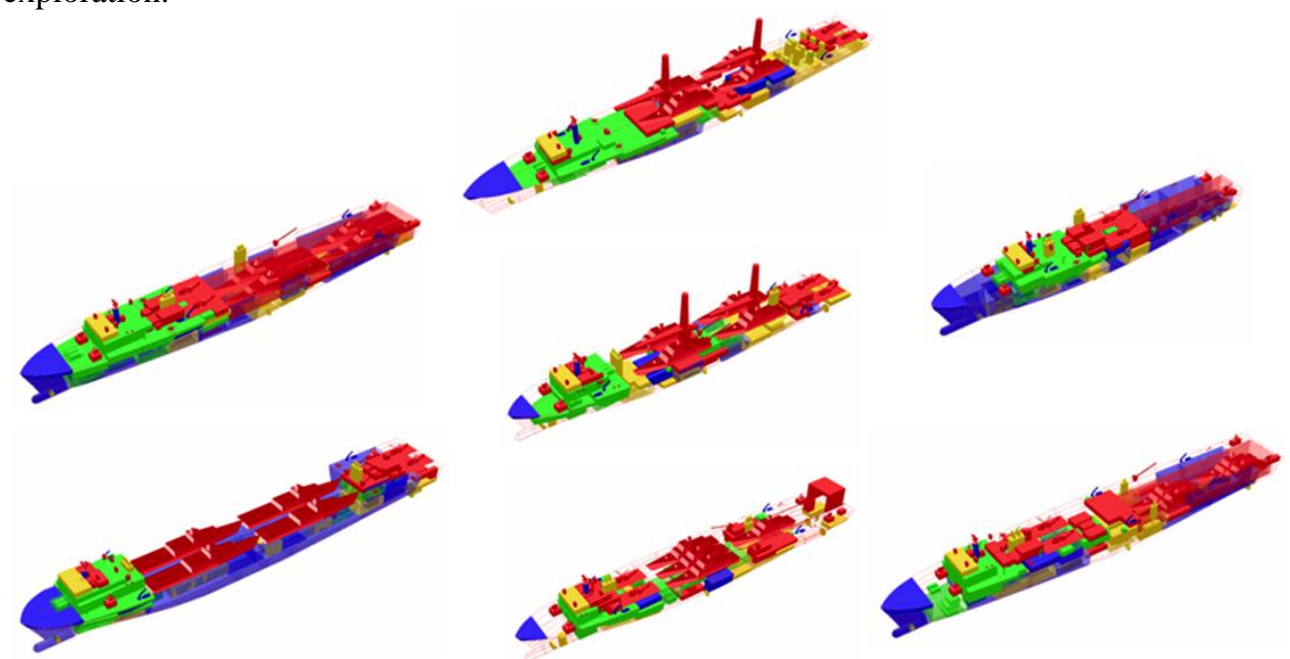

Figure 13: SURFCON Models of UCL DBB Studies for Littoral Mothership Investigation

(Andrews \& Pawling 2004)

\section{EXAMPLES OF UCL CONCEPT STUDIES EXPLORING ASPECTS OF STYLE}

This section outlines results of investigations into a selected set of the topics in Table 1, which have been the subject of discrete ship design studies by the author's research team at UCL over the last two decades. The items outlined are not a comprehensive analysis of the Table 1 topics, but are intended to show how some of these various design issues can be seen as key design choices over which the ship designer ought to be more informed. Thus the designer could make the key first decision step in the ship design process, summarised in Figure 2, more overtly and in a better informed manner, as a result of such studies for particular new ship designs.

\subsection{MARGINS}

An exploration into the validity of the Design Spiral, as a representation of the nature of ship design especially in ESSD, considered Growth and Board Margins for a naval combatant study (Andrews et al, 2012). Two distinct design styles were investigated: a conventional frigate style and a large hulled/small superstructure variant. The former showed a linear behaviour in solution size with increasing Board Margin (i.e. the allowance for future capability updates), while the latter showed a discernible step change in size with the same variable (see Figure 14). Thus the choice of overall style was shown to be key to any such investigations and was only revealed by the use of the DBB approach, rather than simple numerically ship synthesis, which had been undertaken on a frigate study of varying Board Margin several decades previously (Andrews, 1984).

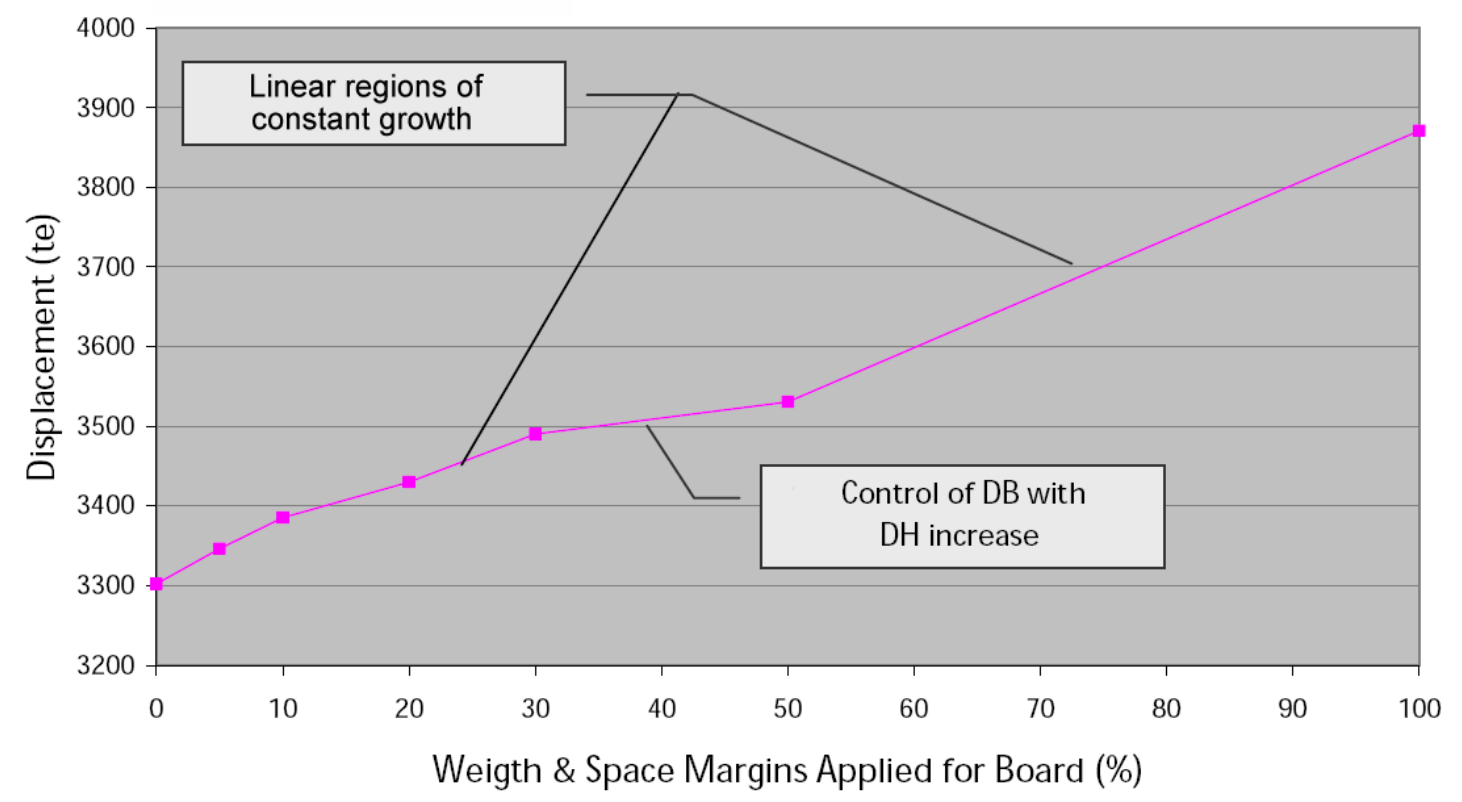


Figure 14: Example of Non-Linearity in Margin growth as Style Choice (Andrews et al, 2012)

\subsection{COMMERCIAL STRUCTURE VERSUS SHOCK ROBUSTNESS \\ In considering the extent to which commercial standards} might be introduced into naval ship design, in the search for reductions in initial (procurement) cost, this UK EPSRC CASE funded project (Bradbeer and Andrews, 2010) first considered the effect of missile attack on a small frigate built to commercial standards. It was found that survivability was affected by the density of outfitting, where the latter could be considered as due to a style decision, akin to building in robustness or adaptability. A second investigation (Bradbeer and Andrews, 2012) looked at the effect of underwater shock and varied the structural style from normal naval scantlings to commercial practice (see Figure 15). This meant changing from closely spaced "Tee bar" stiffeners adopted to reduce the structural weight fraction to wider spaced larger bulb and flat bar stiffeners. The survivability to very high (hull lethality) shock levels due to adopting such differing scantling styles, yet with the same longitudinal bending strength, was found to be considerably less for the heavier but less structurally effective commercial style. This is an example of more detailed analysis than would normally be undertaken in ESSD, but reveals that a style decision taken early in design can make a major difference in a key ship's capability, which has been seen to be fundamental in a naval combatant.

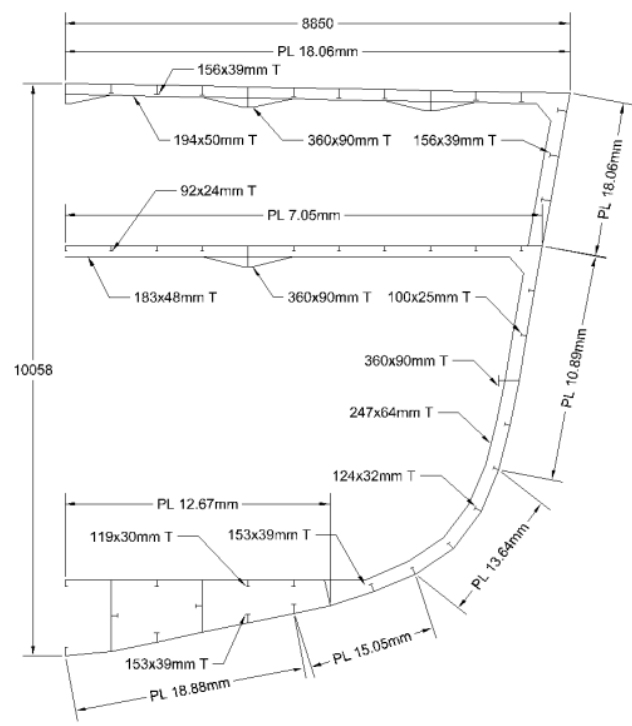

a. Naval Tee bars

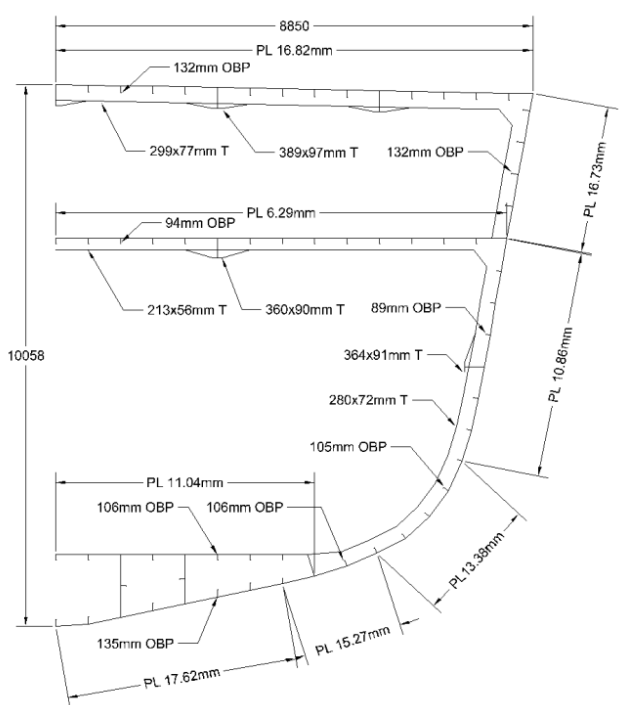

b. Commercial Offset Bulb Plate sections

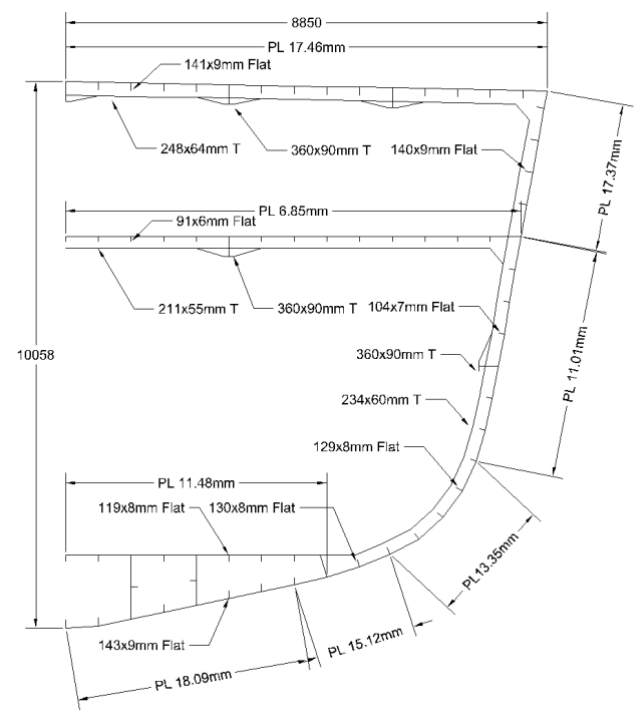

c. Commercial Flat bar sections

Figure 15: Comparison of Naval and Commercial Structural Styles

(Bradbeer \& Andrews, 2012)

\subsection{DESIGN FOR PRODUCTION - DESIGN STYLE DOMINATED}

In a research project funded by the UK Shipbuilders and Ship-repairers' Association (Andrews et al, 2005) a study was undertaken on both commercial vessel and naval ship ESSD to improve the architecture of ships to reduce the cost of outfitting. This was a novel study in that much of large commercial ship cost is in steelwork, whereas for complex ships, such as the Corvette and the Offshore Support Vessel (OSV) in this study (see Figure 16), much of the cost is in outfitting, and hence amenable to architectural exploration. The styles of both ship types 
were investigated, with rearranged machinery location and more spacious passageways to fleet in modular cabins, respectively, which could be seen as specific style choices.

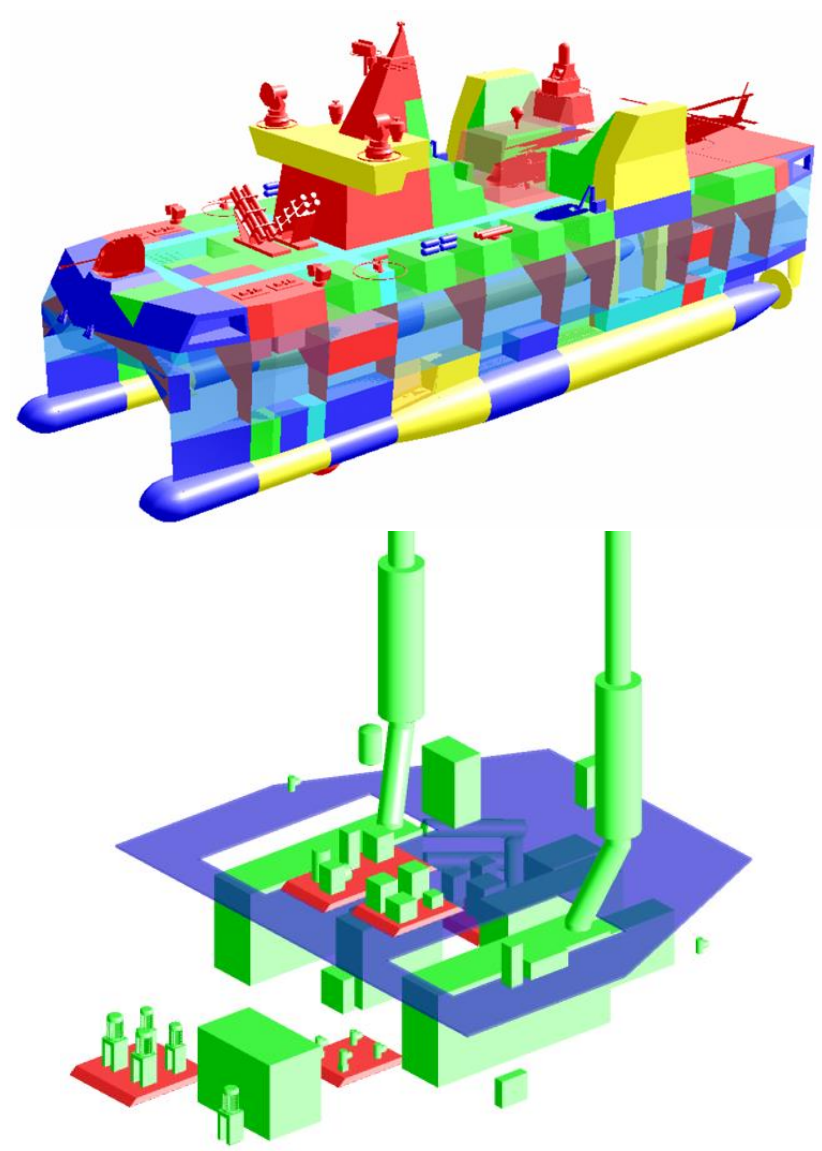

Figure 16: Examples of Style emphasising Producibility in ship configuration (Andrews et al, 2005)

\subsection{OFFSHORE PATROL VESSEL (OPV) CONFIGURATION STYLE}

This ESSD investigation (Pawling and Andrews, 2010) was undertaken to show that in addition to the conventional OPV, based on the style of small naval combatants, it was worth exploring more radical ship configurations, such as the OSV commercial design, a trimaran OPV and a very wide stern (Ramform like) mono-hull (see Figure 17). These alternative configurations could be seen to be addressing style issues, such as commercial design style and different hull forms, in exploring solutions which might be more appropriate for stowing and deploying sizeable autonomous vehicles, especially launch and recovery from the vessel's stern.

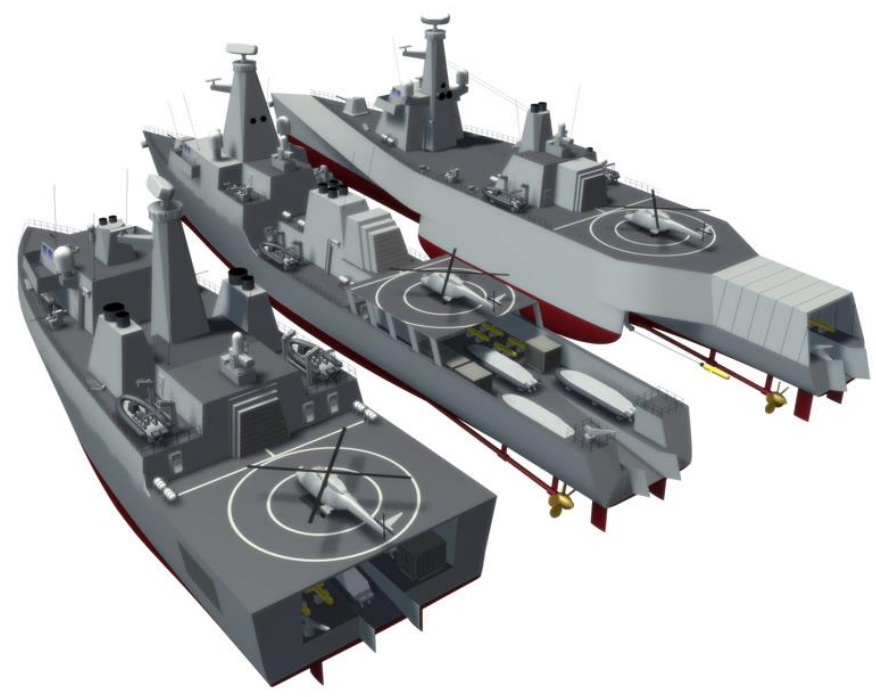

Figure 17: Examples of different Ship Configuration Styles for an OPV Study (Pawling and Andrews, 2010)

\subsection{SURVIVABILITY}

There are many style choices related to survivability in the design of naval vessels. In fact it could be argued that beyond the carriage of combat related systems, it is a heightened emphasis in the ship design on Vulnerability reduction measures that truly distinguishes the naval ship from its commercial cousins. As part of that style choice, features addressing most of the issues listed in Column 2 of Table 1 need to be selected, or at least implied, very early in the concept design any such options. Thus features such as the water tight sub-division, adoption of a zoning policy or even the configuration of the main passageways, can be seen as significant style choices. Figure 18 shows a comparison of main passageway arrangements explored in a personnel movement exploration for a Type 22 Frigate, which is characterised by having two passing decks in the main hull over the machinery spaces (Andrews et al, 2008). 


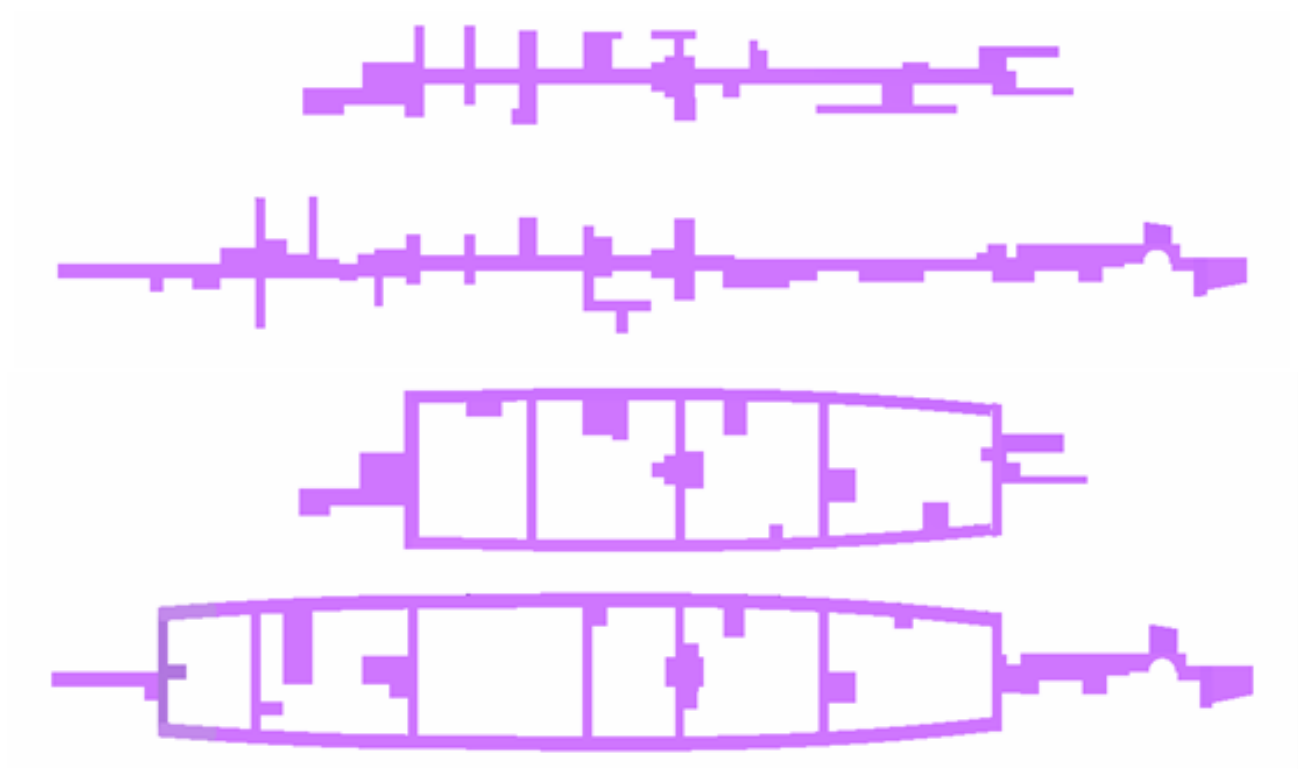

Figure 18: Examples of Single Central and Double Passageways for Type 22 Frigate (above) and variant (below) (Andrews et al, 2008)

\subsection{MOTHERSHIP}

\section{CONFIGURATION/OPERATIONAL STYLE}

A novel solution to the fast Littoral Combatant concept was seen to be the transporting of several small craft on a large fast vessel. This study (Andrews and Pawling, 2004) with five distinct ship configurations with different launch and recovery methods has already been shown in Section 4.4. The alternative styles were proposed as an exploration of the operational options through alternative design styles.

\section{RECENT DEVELOPMENTS OF RESEARCH INTO SHIP STYLE}

A further feature of style is that, if it can influence multiple areas of design, then it must itself represent the "grouping" of multiple sources of information in some way. Developing an ontology and taxonomy for style is seen to offer potential advantages to the practice of ship concept design, as it could allow for more efficient storage, retrieval and application of potentially disparate pieces of information or decisions (Pawling et al, 2013). It has been proposed that this could be combined with the semi-automatic layout generation methods, such as that developed by TU Delft (van Oers, 2011), to allow a broader exploration of the impact of stylistic decisions in ESSD than the point based architecturally design approach using DBBs.

From the some of the above examples of ship architecture, it is considered that for some of these designs there were significant choices made which could be seen to be highly stylistic. Furthermore, such decisions as the number of masts on a frigate, or how the various functions might be disposed around an enclosed hangar on an aircraft carrier (see Figure 10), are highly cross-cutting in impact. This is because such style choices can have both direct and indirect implications on a wide range of overall and detailed design features.

There are seen to be two aspects where a more focused consideration of style might improve ESSD (Pawling et al 2013). Firstly, the development of semi-automatic methods of generating sufficiently detailed designs but based on an initially simplified layout, rather than $a b$ initio and genetic algorithm based such as the TU Delft approach above. The former would allow the designer to better focus on the overall style of the arrangement. Secondly, a style focused taxonomy could be used as a method for describing and storing the data and rules that permit such semi-automatic tools to be used in developing more detailed layouts, such as that in Figures 12 and 16. The designer could then apply a wide range of changes to a design option by selecting different style aspects (e.g. different survivability levels or the extent of through life adaptability - see Table 1). These could then be compared to give insights into major design and cost drivers in ESSD.

\subsection{A PROPOSED INTEGRATED APPROACH TO BETTER STYLE DRIVEN DESIGN}

An approach, to better consideration of style choices, was made by the UCL design research team, in conjunction with its research partners the University of Michigan and TU Delft (Pawling et al, 2013). Current early stage design techniques for initial general arrangement definition focus predominantly on spatial compartment allocation. When evolving general arrangements, there is a need to be able to introduce detailed style decisions once the selected overall ship style has been made (see Figure 2). Given that style at the level below that overall configurational style can be defined as the combination of whole ship performance metrics and local system metrics (see Table 1), information can be drawn from different domains, much of which may be ill-defined knowledge 
(such as many human factors aspects). Style is representative of design intent and the designer's engineering judgment in the early stages of ship design constraint definition, layout generation, and in the evaluation of the evolving layout. With the ability to account for style definition, the designer might then be able to create concept designs that integrate a larger body of design intent, without the need to explicitly describe its characteristics.

In an effort to incorporate style into the early stages of concept design, an iterative method using three primary levels in the design process was proposed. Figure 19 shows those levels as the style elucidation and input definition level, design layout generation method level, and post-generation style analysis level, respectively. Multiple components of coupled analysis would allow the cross cutting of knowledge to capture style attributes over multiple domains of the design within each level of the suggested process.

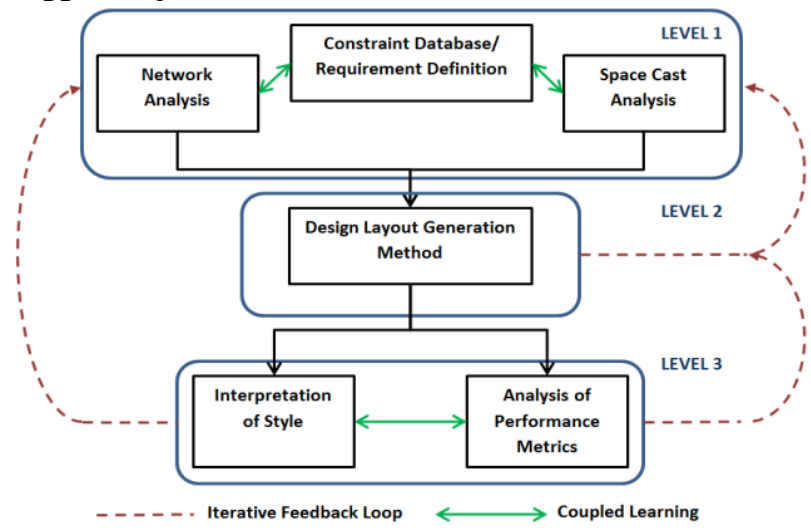

Figure 19: Proposed integrated approach for style definition in early stage design

(Pawling et al, 2013)

The first level of Figure 19 highlights the style choices and the production of the inputs for the design generation method. Capturing the style is done through the explicit and implicit definition of the parameters that will drive the analysis of performance metrics, and their stylistic or architectural features. Definition of these constraints and requirements has not been seen to be a trivial process as they evolve throughout the early stages of ship design and then right through to detailed design. One increasingly popular ways to define constraints and requirements is through the use of network analysis. A network, in its broadest sense, is a collection of points joined by lines which can then be represented in a matrix form and therefore able to be analysed (see Pawling et al. (2016) for a summary, including applications to ship design, and Newman (2010) for the definitive textbook). At the first level, the relationships between spatial, geometric, and global location preferences are iteratively updated with each completed loop of the integrated approach. The relationships could be investigated abstractly through a network analysis alongside geometric allocation.. Insights gained during this definition level could then be used to guide the elucidation process towards the novel definition of style intent in ESSD. Currently networks are being applied to both vessel configurations and distributed ship service systems (Gillespie, 2012, Collins et al, 2015).

Style at this level could identify any ill-defined knowledge early in ship design and capture, as inputs, hard to quantify metrics. The definition of style could be carried through to Level 2 and Level 3 of Figure 19, coupling ship performance metrics to the architectural layout generated to then down select appropriate designs. With proper definition of inputs and a clearly selected ship design style, the parameters of the constraints and requirements would give the potential to produce designs with higher integrity for the subsequent phases of ship design beyond ESSD.

\section{CONCLUSION}

The paper has focused on an important part of design decision-making, that of style choice. This has been addressed through discussing actual ship designs in history and specific ship research investigations on discrete ship style related issues, recently undertaken at UCL. A way forward proposed in an early joint paper with collaborators has been seen as a means to further emphasise this paper's assertion that choice of overall design style is probably the key design decision. A clearer decision choice on style should be made (hopefully) explicitly at the earliest step in starting any design option to ensure better design exploration and, hence, a better focused downstream process.

\section{REFERENCES}

ANDREWS, D.J. (1981), Creative Ship Design, Trans RINA Vol. 123, 1981.

ANDREWS, D.J. (1984), Synthesis in Ship Design, PhD University of London.

ANDREWS, D.J. (1986), An Integrated Approach to Ship Synthesis, Trans RINA Vol.128, 1986.

ANDREWS, D.J. (1994), Preliminary Warship Design, Trans. RINA Vol. 136, 1994.

ANDREWS, D.J. (2003), A Creative Approach to Ship Architecture, RINA International Journal of Maritime Engineering, Sept 2003, Discussion and Author's response IJME Sept 2004, Trans RINA Vol. 145, 146, 2003, 2004.

ANDREWS, D.J. (2004), Multi-Hulled Vessels, Chapter 46 of "Ship Design and Construction" Lamb T (Ed): SNAME New Jersey, Vol. 2, Summer 2004.

ANDREWS, D.J. (20110

ANDREWS, D.J. (2013), The True Nature of Ship Concept Design - And what it means for the Future Development of CASD, COMPIT 2013, Cortona, Italy, 2013.

ANDREWS, D.J. \& PAWLING, R. (2003), SURFCONA $21^{\text {st }}$ Century Ship Design Tool, IMDC 03, Athens, May 2003.

ANDREWS, D.J. \& PAWLING, R. (2004), Fast Motherships - A Design Challenge, International 
Conference 'Warship 2004: Littoral Warfare \& the Expeditionary Force', RINA, London, June 2004.

ANDREWS, D.J. \& PAWLING, R. (2008), A Case Study in Preliminary Ship Design, IJME RINA Trans. Vol. 150, Part A1, 2008. Discussion and Authors' reply IJME, Part A3, 2008.

ANDREWS, D.J., BURGER, D. \& ZHANG, J.W. (2005), Design for Production using the Design Building Block Approach, IJME, Vol. 147, RINA, 2005.

ANDREWS, D.J., PERCIVAL, V. \& PAWLING, R. Just how valid is the Ship Design Spiral given the existence of Cliffs and Plateaux?, Proceedings $11^{\text {th }}$ IMDC, Strathclyde University, Glasgow, June 2012.

ANDREWS, D.J. et al (2008), Integrating Personnel Movement Simulation into Preliminary Ship Design, IJME Trans RINA Vol.150 Part A1, 2008. Discussion and Authors' reply IJME, Vol 150, Part A3, 2008.

BAKER, R. (1955), Habitability in Ships of the Royal Canadian Navy, Trans SNAME, 1955.

BRADBEER, N. \& ANDREWS, D.J. (2010), Vulnerability of a Low Cost Combatant converted from a merchant ship, INEC 2010, HM Naval Base, Portsmouth, May 2010.

BRADBEER, N. \& ANDREWS, D.J. (2012), Shock Response Implications of Lower-cost Warship Structural Styles, Proceedings $11^{\text {th }}$ IMDC, Strathclyde University, Glasgow, June 2012. (Revised version)

BROADBENT, G. (1988), Design in Architecture: Architecture and the Human Sciences, London: David Fulton Publishers, Revised edition, 1988.

BROWN, D.K. ((1983), A Century of Naval Construction, Conway Maritime Press, London.

BROWN, D.K. ((1987), The Architecture of Frigates, RINA Symposium on Anti-Submarine Warfare, London, May 1987.

BROWN, D.K. (1999), The Grand Fleet, Chatham Publishing, London 1999.

BROWN, D.K. \& ANDREWS, D.J. (1980), The Design of Cheap Warships, Proc. of International Naval Technology Expo 80, Rotterdam, June 1980. (Reprinted in Journal of Naval Science April 1981)

BROWN, D.K. \& MARSHALL, P. (1978), Small Warships in the Royal Navy and the Fishery Protection Task, RINA Small Fast Warship Symposium, London, June 1978.

COLLINS, L. et al (2015), A new approach for the Incorporation of Radical Technologies: Rim Drive for Large Submarines, IMDC 2015, Tokyo Univ., May 2015.

GILLESPIE, J. W. (2012), A network science approach to understanding and generating ship arrangements in early-stage design, PhD thesis, University of Michigan. H.M.S.O. (1989), Supplementary Estimates Vote 1, Class II: Payments to Harland \& Wolff PLC, House of Commons Defence Committee, Minutes of Evidence, Wed $29^{\text {th }}$ Nov 1989.

HONNOR, A.F. \& ANDREWS, D. J. (1982), HMS INVINCIBLE The First of a New Genus of Aircraft Carrying Ships, Trans RINA Vol. 124, 1982.
HUTCHINSON, G. A. (1981), Study of Internal configuration of Ships, MSc Dissertation in Naval Architecture, UCL, Sept 1981.

KING, A.S. (1985), CAD Layout Exploration, MSc Dissertation in Naval Architecture, UCL 1985.

LEVANDER, K. (2003), Innovative Ship Design, Proc $8^{\text {th }}$ IMDC, Athens, May 2003.

MUNOZ, J.A. \& FORREST, C.J.M. (2002), Advantages of Software Integration from Initial Design Through to Production Design, Proceedings of ICCAS 2002, Malmo, Sweden, Sept 2002.

NEWMAN, (2010)

PARKER, J. (2016), An Independent Report to Inform the UK National Shipbuilding Strategy, London, $3^{\text {rd }}$ Nov 2016.

PAWLING, R. \& ANDREWS, D. J. (2010), Three Innovative OPV Designs Incorporating a Modular Payload for UXVs, International Conference 'Warship 2010: Advanced Technologies for Naval Design and Construction', RINA, London, June 2010.

PAWLING, R. et al, (2013), An Integrated Approach to Style Definition in Early Stage Ship Design, COMPIT 2013, Cortona, Italy, 2013.

PIPERAKIS, A. (2013), An Integrated Approach to Naval Ship Survivability in Preliminary Ship Design, PhD, UCL 2013.

ROACH, J. C. et al, (1979), Visual Effectiveness in Modern Warship Design, USNEJ, Dec 1979.

RYBEZYSKI, W. (2001), The Look of Architecture, O.U.P. Inc, NY, NY.

TUPPER, E. C. (2013), An Introduction to Naval Architecture, 5th Edition, Butterworth-Heinemann, Oxon.

VAN OERS, B. (2011), A packing approach for the early stage design of service vessels, $\mathrm{PhD}$ thesis, TUDelft. 